\title{
Commodities as an Investment
}

\author{
Gerald R. Jensen, CFA \\ Board of Trustees and Professor of Finance \\ Northern Illinois University, DeKalb
}

Jeffrey M. Mercer

I. Wylie and Elizabeth Briscoe Chair in Finance

Rawls College of Business, Texas Tech University, Lubbock

\begin{abstract}
Interest in commodities has grown tremendously, partly because commodities are believed to provide direct exposure to unique factors and have special hedging characteristics. This review discusses the instruments that provide exposure to commodities, the measures and historical record of commodity investment performance, evidence about the benefits of strategic versus tactical commodity allocations, and recent developments in the market.
\end{abstract}

Interest in commodities as an investment asset class has grown tremendously in recent years. Because of the high costs and inconvenience of directly holding physical commodities, investors have traditionally relied on commodity futures (either directly or through investment management firms) to obtain a commodity exposure. Recently, commodity-based exchange-traded products have come to prominence and have facilitated renewed growth in commodity investing. The enormous success of these exchange-traded products is shown by the huge investment in the products, which reached $\$ 125.8$ billion by April 2010 (see Carpenter 2010).

The popularity of commodities as investments is predicated on the view that commodities provide a direct exposure to a number of unique factors and have special hedging characteristics. Specifically, commodity prices are driven by such factors as weather, geopolitical developments, supply constraints in physical production, unanticipated increases in demand as a result of prosperity in emerging markets, and incidents that create political or economic turmoil. Relative to commodities, traditional asset classes are affected by these factors either to a lesser degree or in the opposite manner.

Two primary factors have contributed to the phenomenal recent growth in commodity investments. First, significant advances have been made in the various investment instruments that allow investors to gain an exposure to commodities. Second, two major asset classes, equities and real estate, performed poorly and experienced high volatility following the "tech bubble" in 2000 and the "subprime crisis" in 2008-2009, motivating investors to seek out asset classes that are alternatives to equities and real estate.

In the following sections, we discuss the various instruments available for investors to use in gaining exposure to commodities, the measures used to assess the performance of commodity investments, the historical performance of commodities, research studies that report evidence about the benefits of strategic and tactical commodity allocations, and some recent developments in the market for commodity investments.

\section{Commodity Investment Vehicles}

Investors can gain exposure to commodities through numerous investment vehicles. Many of these instruments have only recently become widely available to both individual and institutional investors. This section provides a brief description of the instruments that offer commodity exposure. 
Exchange-Traded Funds. Commodity-based exchange-traded funds (ETFs) provide investors with a low-cost means of gaining exposure to commodities. These securities represent claims to individual commodities, groups of commodities, or indices tracking commodity prices. The ETFs trade on exchanges like common stocks do. More than 100 such funds exist in the United States. Some of the most popular broad-based commodity ETFs are the following:

- ticker symbol GCC, which tracks the CRB Commodity Index and is offered by GreenHaven Funds,

- GSG, which tracks the S\&P GSCI Commodity Index and is offered by iShares, 1 and

- $\quad$ DBC, which tracks the Deutsche Bank Commodity Index and is offered by PowerShares.

Numerous ETFs that track individual commodities or commodity types are available. Some examples are GLD, the SPDR (Standard \& Poor's Depositary Receipts) Gold Trust, which tracks the price of gold and is offered by StreetTracks; SLV, the iShares Silver Trust, which tracks the price of silver; and DBE, which tracks a portfolio of the most heavily traded energy futures contracts and is offered by PowerShares. There are also ETFs that offer leveraged positions in commodities (e.g., UCD, which promises twice the daily return of the Dow Jones UBS Commodity Index and is offered by ProShares) and those that offer short positions in commodities (e.g., $\mathrm{CMD}$, which promises twice the inverse of the daily return on the Dow Jones AIG Commodity Index and is offered by ProShares).

The underlying instruments for the majority of commodity-based ETFs are futures contracts, but many precious metal ETFs (e.g., the SPDR Gold Trust) hold the actual physical commodity in storage. Furthermore, although most commodity-based ETFs are designed to track commodity prices, a number of ETFs are designed to track the price of the equities of companies whose main product is a commodity (e.g., MOO, which tracks the performance of equities of companies engaged in agribusiness). These equity-based instruments are frequently identified as commodity-related ETFs. Commodity-related ETFs provide a less direct exposure to commodity prices because their value is influenced by commodity prices as well as factors that impact equity prices.

Exchange-Traded Notes. Commodity-based exchange-traded notes (ETNs) are non-interest-paying debt instruments that are similar in purpose to commodity-based ETFs. Like ETFs, ETNs provide a low-cost means for investors to gain exposure to individual commodities or baskets of commodities. Some popular ETNs are UCI, which is offered by UBS and tracks the UBS Bloomberg Constant Maturity Commodity Index; USO, which is offered by Victoria Bay Asset Management and tracks the price of crude oil; and DBA, which is offered by PowerShares and tracks a basket of the most actively traded agricultural commodities.

Although the basic purposes of commodity-based ETFs and ETNs are comparable, investors should be aware of some important differences. First, the price of an ETN is dictated by a contract that stipulates the price relationship between the ETN and the underlying assets. In contrast, ETFs hold the underlying asset (either in physical form or through a derivative instrument). In some cases, ETFs have been shown to diverge from the price of the underlying commodity or commodities; ETNs track the underlying assets more closely because of their contractual link. The contractual nature of ETNs, however, leads to a major difference in credit or counterparty risk between the two instruments. Because ETNs do not hold the underlying asset or a derivative contract on the underlying, the payoff to an ETN depends on the creditworthiness of the issuer of the ETN. Second, the gains and losses on ETFs and ETNs receive different tax treatment in many jurisdictions. Thus, a potential investor in these instruments must research relevant tax law or consult a tax professional.

Mutual Funds. Commodity-based mutual funds provide easy access to commodities in a form that is familiar to the typical investor. Among the early entrants into this business were Oppenheimer, with its Real Asset Fund in 1997, and Pimco, with its Commodity Real Return Strategy Fund in 2002. Commodity-based funds typically use derivative instruments that are based on commodity indices to build their exposure to commodities. In addition, some commodity-related mutual funds invest in the equities of companies whose profitability is tied to commodity prices (for example, Fidelity's Select Natural Resources Fund and Vanguard's Precious Metals and Mining Fund). Commodity-based closed-end funds also exist, but unlike ETFs and open-end mutual funds that closely track net asset value, shares of closed-end funds often trade at a discount or premium to net asset value.

1GSCI is the former Goldman Sachs Commodity Index. 
Structured Notes. Commodity-linked notes are popular with investors wishing to gain exposure to commodities without having to bear all of the price risk inherent in commodities. Commodity-linked notes combine the security of a fixed-income instrument with an exposure to commodities, generally in the form of an option or futures contract tied to a commodity index. The notes are non-interest-bearing instruments, and their maturities typically vary from one to five years. On the maturity date, the note pays the initial principal amount plus a return based on the price change of the underlying commodity instrument. Structured notes avoid some of the tax complications that plague commodity futures and thus offer an attractive feature for institutional investors (particularly, mutual funds). Structured notes are debt instruments and are frequently unsecured, however, so the creditworthiness of the issuer is of utmost importance. As with ETNs, concern about the counterparty or credit risk of the issuers can limit the liquidity of the market for these instruments.

Derivative Contracts. Futures and options contracts with commodities as the underlying asset provide investors with a way to allocate funds to individual commodities and baskets of commodities (commodity indices). Commodity indices consist of passive, rebalanced, long positions in baskets of commodity futures. In addition to exposure to commodity indices provided by ETFs, ETNs, mutual funds, and commodity-linked notes, investors can enter into derivative contracts directly on the indices. For example, the CME Group offers futures contracts on the S\&P GSCI, which consists of futures contracts on 24 individual commodities and is by far the most popular of the various commodity indices. Direct positions in derivative contracts on commodity indices are popular with institutional investors that wish to gain a broad exposure to general commodity prices. For decades before the introduction of the securities discussed in the foregoing sections, investment in commodity-based futures contracts was the primary means by which institutional investors accessed the commodity markets.

Swaps. Commodity swaps are over-the-counter agreements to exchange cash flows in which the cash flows depend on a notional (principal) dollar amount and changes in commodity prices. These instruments are generally used by institutions (such as pension funds and investment companies) to gain exposure to commodity prices. Because the instruments are not exchange traded, the creditworthiness of the counterparty is a consideration.

Commodity Pool Operators and Commodity Trading Advisers. Unlike the investment vehicles discussed so far, which provide passive exposures to commodities, investors can gain an actively managed exposure to commodities by investing with a commodity pool operator $(\mathrm{CPO})$ or by hiring a commodity trading adviser (CTA). CPOs are enterprises that collect and pool funds from a number of investors for the purpose of trading commodity-based futures and options contracts. CTAs are registered with the U.S. Commodity Futures Trading Commission as investment advisers and are frequently employed by investment managers and CPOs to assist in developing active strategies for trading commodity-based derivatives. Edwards and Park (1996) and Edwards and Liew (1999) discuss the structure, performance, and costs associated with commodity investments obtained via CTAs and CPOs. Unlike commodity index investments, CTAs and CPOs often hedge their exposure to commodity market risk (commodity beta) in their search for alpha and thus cannot always be used to provide generic commodity exposure.

Equities of Commodity-Based Companies. A common way to gain commodity exposure is to invest in the equity of a company whose main product is a commodity. This approach offers a low-cost and convenient method to gain commodity exposure, which may explain its long-standing popularity with investors. For example, purchasing equity in Exxon Mobil Corporation offers an indirect exposure to the price of oil, whereas purchasing equity in Barrick Gold Corporation offers an exposure to precious metal prices. Although investing in the equities of commodity-based companies offers a simple approach to garner commodity exposure, empirical evidence suggests the exposure is somewhat limited. In particular, Gorton and Rouwenhorst (2006a) find that during the 1959-2004 period, commodity-based equities were more closely correlated with the S\&P 500 Index (0.57) than with a commodity futures index $(0.40)$. This evidence indicates that commodity-based equities offer 
less diversification potential than those instruments that are more directly linked to commodities. A possible explanation for this reduced diversification potential is that commodity-producing companies frequently engage in strategies to hedge exposure to commodity price changes.

Direct Investment in Physical Commodities. Investing directly in physical commodities is generally considered not feasible for investors because of the costs associated with trading, insuring, and storing the commodity. Thus, direct investment in physical commodities represents an inconsequential portion of aggregate investor portfolio value. The one exception is the many investors who purchase and hold significant amounts of precious metal in its pure physical form (e.g., gold bullion) or as currency (e.g., silver coinage). To take advantage of this fact, some firms now even sell gold bars in vending machines, called "investment stations."

\section{Assessing the Performance of Commodities}

The two primary methods of analyzing a commodity investment are (1) comparing the commodity returns with those of a proxy (generally, an index) and (2) assessing the sources of return in commodity futures.

Commodity Return Proxies. The most common way of evaluating the performance of a commodity investment is to compare the performance with that of a commodity index. Indices differ substantially in their construction methodology, which largely explains the differences in commodity index performance. Schneeweis, Spurgin, Das, and Donohue (2008) list these differences as follows:

- Index constituents: The specific futures contracts included in the indices vary.

- Selection criteria: Examples include importance to the global economy, liquidity, and trading history.

- Weighting scheme (value based versus quantity based): Value-based indices change the number of contracts in the index so that each component's weight stays fixed. Quantity-based indices keep the number of contracts in the index constant, and each component's weight changes continuously.

- Roll schedule: Because futures contracts expire and need to be replaced in the index, the timing, frequency, and length of the time window within which a given contract is rolled into the next one varies among indices.

- Average maturity: Although many of the major indices hold nearby contracts (i.e., the contracts next to expire), some indices hold deferred (i.e., more distant) contracts, so the average maturity of the component contracts may vary among indices. (See Mouakhar and Roberge 2010 and Ma, Mercer, and Walker 1992 for evidence on the significance average maturity has for performance.)

- Energy allocation: The allocation to the energy sector varies significantly among the indices and has been a major factor in explaining differences in index performance.

Three well-known commodity futures indices are the S\&P GSCI, the Dow Jones-UBS Commodity Index (DJ-UBSCI), and the Reuters/Jefferies CRB Index (RJ-CRBI). The GSCI and the DJ-UBSCI are traded on the Chicago Mercantile Exchange's (CME) Globex, and the RJ-CRBI is traded on the InterContinental Exchange (ICE). Many ETFs (and ETNs) and mutual funds are benchmarked to these indices-for example, Oppenheimer's Commodity Strategy Total Return Fund (ticker QRAAX), Pimco's Commodity Real Return Strategy Class A Fund (ticker PCRAX), and BlackRock's iShares S\&P GSCI Commodity-Indexed Trust ETF (ticker GSG).

The S\&P GSCI is composed of 24 constituent futures contracts ( 6 energy, 5 industrial metals, 8 agricultural, 3 livestock, and 2 precious metal), and $\mathrm{S} \& \mathrm{P}$ weights the constituent contracts by world production. These weights are adjusted slightly once a year. The index always invests in the contract nearest to expiration (the nearby contract) and, at the beginning of its expiration month, rolls forward into the next nearby contract between the fifth and ninth business day of the month prior to delivery.

The GSCI is the most heavily relied on commodity index, but its weighting method is commonly criticized by its detractors. In particular, because the GSCI is production weighted, the index is heavily tilted toward energy contracts and, therefore, the index is quite sensitive to changes in the price of oil. For example, in the 1983-2009 period, the correlation in monthly returns between the GSCI and the energy component of the GSCI was 0.94. 
The DJ-UBSCI is composed of 19 constituent contracts (6 agricultural, 4 energy, 3 industrial metals, 2 precious metals, and 2 livestock). It constrains any one commodity to a 15 percent maximum weight and constrains any one sector to a 33 percent maximum weight. The constituent weights are determined by liquidity and production criteria. The index always invests in the nearby contract and, at the beginning of its expiration month, rolls forward into the next nearby contract between the fifth and eighth business day of the month prior to delivery.

The RJ-CRBI is composed of 19 constituent contracts (2 precious metals, 3 industrial metals, 2 livestock, 4 energy, and 8 agricultural). The index weights are fixed in a discretionary manner across the five subsectors and rebalanced monthly (e.g., the energy contracts currently have a total weight of 33 percent). The index always invests in the nearby contract, and at the beginning of its expiration month, it rolls forward into the next nearby contract between the first and fourth business day of the month prior to delivery.

Components of Commodity Futures Returns. The sources of return in commodity futures investing are generally three components: (1) change in spot price, (2) return on margin collateral, and (3) roll return. Because futures prices are necessarily co-integrated with spot prices and must converge to the spot price at contract expiration (i.e., the basis must go to zero), the change in the spot price is a key component of return. ${ }^{2}$ Typically, researchers consider the return on short-maturity risk-free securities (U.S. T-bills) to be a component of the total return because the margin collateral that must be deposited by the investor pays this rate of return. Adding the T-bill return creates an "unleveraged" total return, which can be compared with unleveraged holdingperiod returns on other securities, such as equities and bonds. Roll returns (often referred to as the "roll yield") are the profits or losses stemming from rolling the expiring contract into its replacement. Although estimates vary, depending on the sample, evidence from long-term studies finds the historical roll return to be approximately 4 percent, the spot price appreciation to be near 2 percent, and the collateral yield to be approximately 6 percent. The roll return can turn negative, however (as is currently the case for several commodities), and the collateral yield can vary widely.

The sign and size of the roll return is driven by the relationship between the futures price and the expected spot price. A market is in backwardation if the spot price is above the futures price or if the nearby futures price is above prices on more distant futures contracts. In this case, if an index is long the nearby contract and will roll into more distant contracts when the nearby is about to expire, the roll return will be positive. This scenario is consistent with Keynes' (1930) theory of normal backwardation, in which commodity producers, as hedgers with inventory, are short futures contracts. To entice speculators to take the long position and provide price insurance to the producers, the futures price, to provide compensation to speculators, is below the expected spot price.

The theory of storage, originally set forth by Kaldor (1939), links inventory levels to the term structure of forward prices. This theory similarly predicts positive risk premiums from backwardation but attributes the relationship to a low level of inventories for the commodity. See Fama and French (1988), Ng and Pirrong (1994), and Gorton, Hayashi, and Rouwenhorst (2008) for evidence supporting the theory of storage.

In contrast to backwardation, a market is in contango if the spot price is below the futures price or if the nearby futures price is below prices on more distant futures contracts. In this case, if an index is long the nearby contract and will roll into more distant contracts near expiration of the nearby, the roll return will be negative. This scenario is consistent with the notion that commodity consumers, as hedgers with a future commodity need, are long futures contracts. To entice speculators to take the short position by providing compensation and provide price insurance to the consumers, the market sets the futures price above the expected spot price. Alternatively, the theory of storage would attribute the negative risk premium to a high level of inventories for the commodity.

\footnotetext{
2If a linear combination of two series that are both individually integrated (each has a unit root) is integrated of a lesser order (i.e., stationary), then Engle and Granger define the two series as being co-integrated (Robert F. Engle and Clive W.J. Granger, "Co-Integration and Error Correction: Representation, Estimation and Testing," Econometrica, vol. 55, no. 2 [March 1987]:251-276). That futures and spot prices are co-integrated is well established.
} 
Because price patterns for both backwardation and contango may be viewed as stemming from hedging pressures (in opposite directions), disequilibrium theories of roll return are often generalized as the "hedging pressure hypothesis." De Roon, Nijman, and Veld (2000) find evidence that hedging pressure significantly affects futures returns.

More formally, the sign and size of the roll return is associated with the "cost of carry" pricing relationship between spot prices and futures prices of storable commodities and is associated with whether the relationship is at "full carry." The basic arbitrage-free pricing relationship between spot prices and futures prices of storable commodities dictates that the futures price must be no greater than the current spot price plus the costs associated with carrying the commodity forward to delivery. These costs include financing, storing, transporting, and insuring the commodity. A contract is priced at "full carry" if the futures price equals the spot price plus carrying costs (gold, for example, is a storable commodity that is typically priced at full carry). When a "priced" benefit is associated with holding the physical commodity, the benefit is referred to as a "convenience yield." An example of such a benefit is the potential profit from having physical inventory of a commodity when it is demanded by consumers or needed for a manufacturing process. In this case, the futures price is below full carry and can, in fact, be lower than the spot price (i.e., backwardation). For example, if inventories of a commodity are tight prior to a predicted period of high demand, holding inventory provides a tangible benefit that is priced, which leads to backwardation. Again, this condition provides subsequent positive roll returns. Thus, the theory of storage and the role of convenience yields (relative to the size of the other carrying charges) and the theory of backwardation (and contango) affect the sign and size of roll returns in storable commodities.

Given the preceding discussion, the following question naturally arises for a storable commodity priced at less than full carry: Can such a commodity be arbitraged? That is, could one, to generate a risk-free return, simultaneously sell the commodity short, lend the short-sale proceeds, and buy the futures contract (which, when the contract was delivered at expiration, would allow one to return the physical commodity)? This strategy is called a "reverse cash-and-carry arbitrage," and the answer is no. The key to the answer is to recall that the price differential is (in this instance) caused by the presence of the convenience yield. If the producer holds physical inventory but does not benefit from holding it between now and the futures expiration and if the current spot price exceeds the futures price, the producer will choose to sell the inventory now and simultaneously buy the futures contract, earning the price differential and avoiding the storage costs. However, the benefit of having the physical inventory (e.g., natural gas inventory when facing the possibility of unusually cold weather) will cause the producer to carry, or hold, the inventory rather than sell it. Because the arbitrage requires selling short the physical commodity, it cannot be accomplished because the presence of the convenience yield makes this strategy costlyor even impossible.

\section{Historical Investment Performance of Commodities}

Numerous studies have evaluated the performance of commodities as a stand-alone investment, and the results have varied substantially among the studies. To reexamine commodity stand-alone performance, we derived performance results over a 40-year sample period, which is considerably longer than the period examined in most previous research. Table 1 presents the performance characteristics of several commodity futures subindices relative to the U.S. equity market as reflected in the S\&P 500 and the developed non-U.S. equity market as reflected in the Europe/Australasia/Far East (EAFE) Index. In the following paragraphs, we discuss the performance data reported in Table 1 and relate the findings to the findings of previous research.

Table 1 indicates that, on average, over the past 40 years, a commodity investment (in the form of futures contracts) had a risk-return trade-off that compared favorably with that of equities. In particular, commodities earned higher average returns than the two equity indices; however, the volatility of returns has also been higher. On a risk-return basis, the coefficient of variation (standard deviation/mean return) for the GSCI, the S\&P 500, and the EAFE Index is, respectively, 5.89, 6.73, and 5.30, which places the GSCI between the two equity indices 
Table 1. Investment Performance of Commodities and Equities: Monthly Data, 1970-2009

\begin{tabular}{|c|c|c|c|c|}
\hline Index & $\begin{array}{l}\text { Mean } \\
\text { Monthly } \\
\text { Return }\end{array}$ & $\begin{array}{l}\text { Standard } \\
\text { Deviation }\end{array}$ & Skewness & Kurtosis \\
\hline GSCI & $0.979 \%$ & $5.763 \%$ & 0.082 & 2.858 \\
\hline Energy & 1.180 & 9.315 & 0.434 & 1.873 \\
\hline Livestock & 0.768 & 5.223 & 0.056 & 1.556 \\
\hline Agriculture & 0.523 & 5.851 & 0.741 & 3.713 \\
\hline Metals & 0.964 & 7.038 & 0.553 & 4.164 \\
\hline Precious metals & 0.816 & 6.692 & 1.218 & 7.732 \\
\hline S\&P 500 & 0.669 & 4.497 & -0.458 & 1.931 \\
\hline EAFE & 0.934 & 4.947 & -0.323 & 1.215 \\
\hline
\end{tabular}

Notes: The returns for the GSCI subindices are total returns, which represent the return to a fully collateralized, unleveraged investment in futures contracts. The GSCI energy, metals, and precious metals subindices start in, respectively, January 1983, January 1977, and January 1973.

in terms of risk-return trade-off. This evidence confirms the findings reported in previous research that the longterm return performance of commodities has been comparable to that of equities (e.g., Ankrim and Hensel 1993; Greer 2000; Gorton and Rouwenhorst 2006a).

As indicated in Table 1, the energy subindex performed exceptionally well during the sample period; its mean monthly return (1.18 percent) exceeded the next best performing commodity component (metals, which refers to base or industrial metals) by more than 20 bps per month. Given the heavy reliance of the GSCI on the energy sector, the strong performance of the GSCI can be largely attributed to the extraordinary performance of energy.

Previous studies have noted the tendency for commodity returns to vary considerably over time, an observation consistent with the relatively high standard deviations reported for the commodity subindices in Table 1 . It is not surprising that the commodities demonstrating the most volatility are energy, metals, and precious metals. The demand for energy and metals is closely tied to economic activity and input prices; thus, the prices of these commodities fluctuate with changes in economic conditions. Precious metals are viewed largely as a safe haven for investors, and the demand for precious metals is heavily affected by investor confidence in the security markets and the stability of fiat money's value. Hence, fluctuations in investor confidence produce substantial swings in the price of precious metals.

A commonly acknowledged feature of commodities is that they tend to exhibit positively skewed return distributions (see Erb and Harvey 2006; Gorton and Rouwenhorst 2006a). Because positive skew indicates that relatively large positive returns tend to be more common than relatively large negative returns, investors view this characteristic of commodities favorably. The positive skew results because commodities are viewed as having positive event risk; that is, commodity prices generally react positively to extraordinary detrimental events, such as natural disasters and political and economic crises. Although Table 1 shows the distribution of the GSCI composite index to be only slightly positively skewed, several of the components have high positive skew values. In particular, the agriculture and precious metals subindices have positive skew values of, respectively, 0.741 and 1.218. (A series that is not skewed at all has a skew of zero.) The large positive skew value for the precious metal subindex helps explain the investment popularity of precious metals. Crises, which generally have a negative impact on traditional securities, tend to have a positive impact on precious metal prices. In contrast to commodities, equity return distributions are generally acknowledged to display negatively skewed return distributions. We observe relatively large negative skew values for both the S\&P 500 and EAFE, the respective values being -0.458 and -0.323 . Thus, the positive skew of commodity distributions is frequently considered a highly desirable property for investors whose portfolios are dominated by the negative skew that characterizes equity distributions. 
Kurtosis indicates the tendency for the tails (outliers) of a return distribution to be more populated with observations (to be fatter) than in a normal distribution. Consistent with previous findings (e.g., Gorton and Rouwenhorst 2006a), the commodity subindices in Table 1 exhibit higher kurtosis than the equity indices. The precious metal subindex has an especially high kurtosis value, indicating that extreme returns are a relatively common occurrence for precious metals. This evidence, once again, supports the proposition that commodities tend to exhibit a relatively high level of risk on a stand-alone basis.

The major benefit associated with commodities is generally identified as the low correlation that they exhibit with the traditional asset classes. The low correlation indicates that commodities provide diversification benefits when combined with traditional assets in a portfolio. Table 2 reports correlation coefficients between the traditional asset classes, inflation, the GSCI, and each of the GSCI's component indices. Based on arguments in Gorton and Rouwenhorst (2006a) and Edwards and Liew (1999), we used overlapping annual return data to measure correlations. Gorton and Rouwenhorst state, "Because commodity futures returns are volatile relative to inflation, the long-term correlations better capture the inflation hedging properties of a commodity investment" (p. 54). ${ }^{3}$

Table 2. Correlation of Commodities with Traditional Assets and Inflation: Correlation Coefficients, 1970-2009

\begin{tabular}{lcccccc}
\hline & GSCI & Energy & Livestock & Agriculture & Metals & $\begin{array}{c}\text { Precious } \\
\text { Metals }\end{array}$ \\
\hline S\&P 500 & 0.034 & 0.112 & $0.216^{*}$ & -0.078 & 0.159 & -0.065 \\
EAFE & 0.135 & 0.018 & $0.419^{* * *}$ & 0.021 & $0.260^{*}$ & 0.048 \\
T-bonds & $-0.263^{* * *}$ & $-0.240^{* *}$ & -0.076 & $-0.211^{*}$ & $-0.322^{* * *}$ & -0.220 \\
T-bills & 0.021 & 0.161 & 0.169 & 0.064 & -0.105 & -0.030 \\
Inflation & $0.318^{* *}$ & $0.588^{* * *}$ & 0.166 & $0.372^{* *}$ & 0.115 & $0.411^{*}$ \\
\hline
\end{tabular}

Notes: The GSCI energy, metals, and precious metals subindices start in, respectively, January 1983, January 1977, and January 1973. Newey-West was used to correct standard errors.

*Significant at the 10 percent level.

**Significant at the 5 percent level.

***:Significant at the 1 percent level.

The potential diversification benefits of commodities, which have been identified in previous research, are readily apparent in Table 2. Specifically, the correlations are generally quite low and in several cases are negative; furthermore, the S\&P 500 has a significant correlation with only one commodity subcomponent, the livestock subindex. The correlation between the S\&P 500 and the GSCI composite is a low 0.034 . The lowest correlation with the S\&P 500 occurs for agriculture, which is not terribly surprising because the agriculture sector is relatively independent of economic conditions; it is more dependent on such factors as global weather. This contention is supported by Bjornson and Carter (1997), who find evidence indicating that agricultural commodities provide a natural hedge against business cycles. The very low correlation observed between the S\&P 500 and precious metals is consistent with the view that during periods of investor pessimism investors frequently increase their allocation to precious metals. This increased demand for safety exerts upward pressure on precious metal prices during periods when equities are suffering, in turn supporting the observed negative sign on the correlation coefficient.

EAFE has a higher correlation with the GSCI than the extremely low S\&P 500-based correlation, but the correlation is not statistically significant. The significant correlation between metals and EAFE is likely attributable to the higher proportion of mining and basic material companies in foreign equity markets than in the U.S. equity market. Overall, the low equity-related correlations reported in Table 2 support the diversification potential of commodities as supplements to an equity-based portfolio.

${ }^{3}$ For robustness, we also used monthly returns to calculate correlations. The results for monthly returns are generally consistent with the annual evidence with the exception that the correlations between commodities and inflation are much higher when annual data are used. 
Table 2 shows that the GSCI has low or negative correlations with the fixed-income indices: -0.263 with U.S. T-bonds and 0.021 with T-bills. Furthermore, the correlations between T-bonds and four of the six commodity subindices are negative and statistically significant. Commodities have a considerably lower correlation with T-bills than with T-bonds, an observation consistent with the general rule that long-term bonds are more sensitive to changes in inflationary pressures than short-term bonds. Overall, commodities appear to offer especially attractive diversification potential when added to a portfolio with a heavy fixed-income allocation.

The low correlation between commodities and traditional assets is frequently attributed to the positive association between commodity prices and inflation. A positive relationship is expected because an increase in commodity prices generally increases the costs of producing goods and services, which requires companies to raise prices. In contrast, traditional asset classes tend to be negatively related to changes in the inflation rate. Consistent with this view, in unreported results, we find the correlation between the inflation rate and the returns to the S\&P 500 and EAFE to be -0.111 and -0.091 , respectively; both values are significant at the 5 percent level.

As reported in the final row of Table 2, the composite commodity index (GSCI) has a strong positive relationship with the inflation rate (0.318). This finding is consistent with the results reported in previous research (e.g., Gorton and Rouwenhorst 2006a; Kat and Oomen 2007b). Although significant positive correlations are reported between inflation and each of the commodity subindices, the correlation with the energy component is especially prominent. This result confirms Halpern and Warsager's (1998) finding that energy contracts perform exceptionally well when inflation and unexpected inflation are unusually high. Note, however, that two large energy price shocks occurred in the 1970s, which undoubtedly influenced the correlation. The wide dispersion in the correlations reported in the final row of Table 2 is consistent with Erb and Harvey's (2006) claim that the inflation-hedging potential of commodities varies by commodity type.

Several studies have noted the high level of dispersion in the performance of commodities over time (e.g., Edwards and Park 1996; Edwards and Liew 1999). To assess the consistency of the returns to the commodity subindices, we examined the return distribution attributes of the GSCI and each of its five components during the first and second half of our sample period. The split in our sample period coincides fairly closely with the period when the GSCI became investable, 1992. In July 1992, a futures contract on the GSCI began trading on the Chicago Mercantile Exchange. As noted by Erb and Harvey (2006), returns to the GSCI in periods after July 1992 are tangible, but prior to July 1992 they are only hypothetical.

The first section in Table 3 reports the mean monthly return for the first half (1970-1989) and second half (1990-2009) of the sample period. The GSCI experienced a considerably higher monthly return during the first half ( 1.363 percent) than in the second half ( 0.594 percent). This evidence is consistent with previous findings that commodity performance has been highly inconsistent over time. Furthermore, the findings support Erb and Harvey's (2006) results that commodity returns have been considerably lower in the period since the GSCI began trading as an investable asset. Interestingly, the relatively low return since 1990 is largely the result of the poor performance of commodities during the 1990s. Specifically, since 2000 the mean monthly return to the GSCI (unreported) has been 0.745 percent, which is much closer to the long-term average performance of commodities.

In addition to the identified substantial reduction in commodity returns over time, Erb and Harvey (2006) identify four caveats to projecting past commodity performance into the future. (1) The historical performance of commodities is driven by a relatively few commodities that performed extremely well. (2) The average equalweighted excess return across individual commodities is negative. (3) The return to commodity portfolios is mostly the result of what Erb and Harvey call "diversification return," which is attributed primarily to the process of rebalancing among commodities with low correlations and relatively high volatility. ${ }^{4}$ (4) Commodities have a relatively low and inconsistent relationship with inflation, which provides little support for their effectiveness as an inflation hedge.

4An ongoing debate pertains to whether the diversification return exists as a separate component of the total return on an index or is, instead, a statistical artifact. The case for it being a statistical artifact is available in Gorton and Rouwenhorst (2006b). 
Table 3. Commodity Performance: First Half (1970-1989) and Second Half (1990-2009) of Sample Period

\begin{tabular}{lcccccc}
\hline & GSCI & Energy & Livestock & Agriculture & Metals & $\begin{array}{c}\text { Precious } \\
\text { Metals }\end{array}$ \\
\hline $\begin{array}{l}\text { Mean monthly } \\
\text { lsturn half }\end{array}$ & $1.363 \%$ & $1.856 \%$ & $1.482 \%$ & $1.086 \%$ & $1.253 \%$ & $1.112 \%$ \\
2nd half & 0.594 & 0.944 & 0.058 & -0.041 & 0.776 & 0.564 \\
Standard deviation & & & & & \\
lst half & 5.186 & 8.616 & 6.145 & 6.579 & 8.634 & 8.627 \\
2nd half & 6.274 & 9.554 & 3.989 & 4.969 & 5.782 & 4.433 \\
Skewness & & & & & & \\
lst half & 0.509 & 0.189 & -0.014 & 0.969 & 0.760 & 1.149 \\
2nd half & -0.100 & 0.512 & -0.436 & -0.073 & -0.101 & 0.132 \\
Kurtosis & & & & & & \\
lst half & 3.539 & 1.579 & 1.022 & 3.729 & 3.506 & 5.012 \\
2nd half & 2.244 & 1.985 & 0.462 & 1.148 & 2.044 & 1.900 \\
\hline
\end{tabular}

Note: The GSCI energy, metals, and precious metals subindices start in, respectively, January 1983, January 1977, and January 1973.

An examination of performance of the GSCI components in Table 3 indicates that the energy subindex yielded far superior performance to any other component during both subperiods. The superior performance of this sector supports Erb and Harvey's (2006) contention that the extraordinary past performance of commodities is the result of a few commodities. The agriculture subindex was the worst performer during the two subperiods. During the second half of the sample period, the agriculture and livestock subindices were especially poor performers, whereas the other three indices performed reasonably well.

The second section of Table 3 reports the standard deviations for the two subperiods. The standard deviations show more stability across the two periods than the mean returns show, but the composite has somewhat greater dispersion in the later period. Thus, overall stand-alone performance for commodities, as indicated by risk per unit of return, is much weaker for the later period than for the earlier one. The energy subindex is consistently very volatile in both subperiods, with slightly higher variation in the later period. In contrast, the volatility of the other four components is lower in the second half of the sample period than in the first half.

The GSCI has been criticized for its relatively heavy weighting of energy. The influence of energy is apparent in the mean returns and standard deviations reported in Table 3. In particular, the energy component helps lift the mean return of the GSCI in each subperiod. Furthermore, the high volatility of the energy subindex causes the GSCI in the later period to have a higher volatility than any other component, in spite of the overall GSCI being more diversified.

The results in the third section of Table 3 indicate that positive skew is not a consistent feature of commodities. In fact, only the energy and precious metal subindices report positive skew for both subperiods. Surprisingly, even the GSCI composite index reports a negative skew value for the second half of the sample period. This finding is consistent with Kat and Oomen (2007a), who fail to find evidence of positive skew in commodity return distributions, even though positive skew is a widely advocated advantage of a commodity investment.

The kurtosis values reported in the fourth section of Table 3 indicate that commodities tend to have elevated levels of kurtosis. This feature is also, however, quite inconsistent.

Table 3 indicates that the stand-alone features of commodities exhibit considerable dispersion both by commodity type and over time. What is probably even more relevant to investors, however, is the consistency of the diversification benefits of commodities. 
To evaluate the consistency in benefits over long-term horizons, we analyzed correlations between the commodity indices and the traditional asset classes over the two 20 -year subperiods that make up the sample period. As shown in Table 4, for the majority of subindices, the correlations between commodities and the equity indices (S\&P 500 and EAFE) are fairly consistent in the two subperiods. The exception is the agriculture subindex, which has a far higher correlation in the later period than in the earlier period.

Table 4. Commodity Correlations: First Half (1970-1989) and Second Half (1990-2009) of Sample Period

\begin{tabular}{|c|c|c|c|c|c|c|}
\hline & GSCI & Energy & Livestock & Agriculture & Metals & $\begin{array}{l}\text { Precious } \\
\text { Metals }\end{array}$ \\
\hline \multicolumn{7}{|l|}{$S E{ }^{2} P 500$} \\
\hline 1st half & -0.176 & 0.074 & 0.113 & -0.284 & 0.011 & -0.059 \\
\hline 2nd half & 0.173 & 0.107 & $0.318^{* *}$ & 0.254 & 0.273 & -0.152 \\
\hline \multicolumn{7}{|l|}{$E A F E$} \\
\hline 1st half & -0.050 & $-0.448^{*}$ & $0.399^{* *}$ & -0.192 & -0.004 & -0.080 \\
\hline 2nd half & 0.238 & 0.136 & 0.262 & $0.317^{* * * *}$ & $0.519^{* * * *}$ & $0.350^{* * * *}$ \\
\hline \multicolumn{7}{|l|}{ T-bond } \\
\hline 1st half & $-0.363^{* * *}$ & $-0.424^{* * * *}$ & -0.137 & $-0.309^{* *}$ & -0.193 & -0.248 \\
\hline 2nd half & $-0.200^{*}$ & $-0.219^{*}$ & -0.055 & -0.030 & $-0.558^{* * *}$ & -0.222 \\
\hline \multicolumn{7}{|l|}{$T-b i l l$} \\
\hline 1st half & $-0.340^{* * *}$ & 0.048 & $-0.341^{* *}$ & -0.210 & $-0.493^{* * *}$ & -0.101 \\
\hline 2nd half & 0.146 & 0.168 & 0.291 & 0.131 & -0.029 & $-0.456^{* * * *}$ \\
\hline \multicolumn{7}{|l|}{ Inflation } \\
\hline 1st half & 0.140 & $0.697^{* * * *}$ & $-0.282^{*}$ & $0.289^{*}$ & -0.057 & $0.480^{* *}$ \\
\hline 2nd half & $0.648^{* * * *}$ & $0.578^{* * * *}$ & $0.493^{* * * *}$ & $0.257^{*}$ & $0.335^{* * *}$ & 0.066 \\
\hline \multicolumn{7}{|c|}{$\begin{array}{l}\text { Notes: The GSCI energy, metals, and precious metals subindices start in, respectively, January 1983, January } \\
\text { 1977, and January 1973. Newey-West was used to correct standard errors. }\end{array}$} \\
\hline $\begin{array}{l}\text { *Signific } \\
* * \text { Signific } \\
* * * \text { Signific }\end{array}$ & $\begin{array}{l}\text { at the } 10 \text { pe } \\
\text { at the } 5 \text { perc } \\
\text { at the } 1 \text { perc }\end{array}$ & $\begin{array}{l}\text { level. } \\
\text { level. } \\
\text { level. }\end{array}$ & & & & \\
\hline
\end{tabular}

In general, the equity-related correlations in Table 4 indicate that over the long term, commodity futures have maintained fairly low correlations with equities. The correlations have increased somewhat over time, but even the highest correlations between the S\&P 500 and commodities are only slightly more than 0.30 , which is still a relatively low value. Interestingly, the dispersion across the two subperiods is much greater for correlations of commodities with EAFE than for correlations of commodities with the S\&P 500. And the correlations between commodities and EAFE are higher than the correlations between commodities and the S\&P 500 in both subperiods. Again, this outcome is likely a result of the higher proportion of mining and basic materials stocks in the foreign equity markets relative to the U.S. market.

The correlations between the commodity indices and the fixed-income indices (T-bonds and T-bills) confirm the substantial diversification potential that commodities offer to fixed-income investors. The fixed-incomerelated correlations are generally low or significantly negative and do not change much between the two subperiods. Furthermore, of the correlations between commodities and the fixed-income indices, 10 are statistically significant and all have negative signs.

The final section in Table 4 suggests that the diversification potential of commodities is associated with their close relationship with inflation. Although the correlation between inflation and the six indices differs substantially in the two subperiods and for the six indices, 8 of the 12 correlations are significantly positive. Inflation has a 
much stronger association with commodity prices in the second half, and the stronger relationship is driven largely by the energy, livestock, and metals subindices. This evidence provides support for the contention that commodities serve as a reliable and effective hedge against inflation. Furthermore, the strong and consistent correlation between inflation and energy supports the argument by Halpern and Warsager (1998) that energy futures offer compelling opportunities during periods of heightened inflationary pressures.

\section{Commodity Investment Strategies}

In evaluating the investment benefits of commodities, numerous alternative allocation strategies have been developed and tested. We discuss several alternative allocation strategies, including strategic allocations to commodity indices, tactical allocations based on various commodity characteristics and/or market conditions, allocations to managed commodity funds, and allocations to precious metals - particularly of late, gold.

Strategic Commodity Allocations. Over the years, several researchers have evaluated the benefits of adding a strategic allocation of commodities to an investment portfolio. In the majority of cases, the studies conclude that portfolio performance is enhanced by the addition of a commodity exposure; see Bodie (1983), Ankrim and Hensel (1993), Anson (1999), and Jensen, Johnson, and Mercer (2000).

Jensen et al. (2000) examine the investment benefits of commodities over the 1973-97 period. They find that adding commodities (as proxied by the GSCI) to the investment set allowed investors to achieve a considerably higher mean-variance-efficient frontier. Specifically, the authors show that adding commodity futures to an investment set that included U.S. stocks, U.S. corporate bonds, REITs, and T-bills resulted in an upward shift in the efficient frontier during their sample period. Furthermore, the authors evaluate eight alternative portfolio risk levels for the sample period and find that the optimal allocation in the period to commodities varied from a minimum of 5.6 percent (for the lowest risk portfolio) to a maximum of 36.1 percent (for a moderate risk portfolio) and declined again to 12.2 percent (for the highest risk portfolio).

More recently, Conover, Jensen, Johnson, and Mercer (2010) examine the benefits derived by adding a commodity exposure to portfolios that are based on a variety of equity styles. The authors find that adding a commodity exposure is beneficial regardless of an investor's equity style; however, the allocation must exceed 5 percent to produce a statistically significant benefit. Furthermore, the authors show that the benefit is attributable to a reduction in portfolio risk, not an enhancement in portfolio return. For example, with a 15 percent commodity allocation, the standard deviation of monthly portfolio returns for a growth portfolio falls from 6.19 percent to 5.34 percent while portfolio return increases by a trivial amount.

Tactical Commodity Allocations and Drivers of Return. The studies discussed in the previous section evaluate the benefits associated with adding a strategic allocation of commodities to a portfolio of other assets. In an attempt to determine whether investors can improve performance by timing their commodity allocations, numerous studies have examined alternative tactical approaches that vary the commodity exposure over time. Whereas a strategic allocation is a passive approach to gain commodity exposure, these tactical approaches rely on an indicator, or set of indicators, to actively vary commodity exposure over time. In the following subsections, the tactical approach is identified according to the indicator variable that is used.

Monetary policy/inflation. Jensen, Johnson, and Mercer (2000, 2002) provide a novel contribution to the tactical allocation literature by examining the influence of U.S. Federal Reserve Board monetary policy on the investment benefits of adding the GSCI to portfolios composed of stocks, T-bills, corporate bonds, and REITs. Noting that the prices of physical commodities are, by definition, a component of overall price inflation, the authors suggest that commodity indices can be viewed as an inflation proxy. Furthermore, because developments in actual and expected inflation affect monetary policy, changes in the Fed's monetary policy may affect the role of commodities in portfolios. The authors hypothesize that if the Fed follows a countercyclical policy-raising (lowering) policy rates and taking a "restrictive" ("expansive") policy stance in anticipation of higher (lower) 
inflation-commodities should provide greater benefit in periods of restrictive monetary policy (i.e., when the Fed is raising short-term interest rates). Following Jensen, Mercer, and Johnson (1996), the authors base their $e x$ ante tactical asset allocation rebalancing trigger on changes in the Fed's bank discount rate.

The authors create mean-variance-efficient portfolios (from stocks, T-bills, corporate bonds, REITs, and the GSCI) at eight alternative portfolio risk levels across expansive monetary policy periods and, separately, across restrictive monetary policy periods. They find that the optimal weight in the GSCI in expansive policy periods is zero, or virtually zero, regardless of the desired portfolio risk level; stocks and REITs take most of the weight. In contrast, in restrictive policy periods, the GSCI's optimal weight ranges from 8 percent in the low-risk portfolio to a high of 65 percent in the high-risk portfolio. Interestingly, T-bills are the asset class that takes all of the remainder of the weight regardless of the target portfolio risk level. This result is consistent with the claim that Fed policy is frequently reactionary, so a restrictive policy is adopted in times of higher-than-expected inflation rates, which in turn are associated with high returns for commodities.

In related work, Conover et al. (2010) examine the benefits of adding three alternative passive (GSCI) commodity exposures (5 percent, 10 percent, and 15 percent of the portfolio) to five equity portfolios differing by style over the 1970-2007 period. Because the returns, risk characteristics, and covariances of the equity portfolios differ by style, the authors test for differences in diversification benefits for value, growth, small-capitalization, large-capitalization, and momentum portfolios. The main findings show that (1) in expansive U.S. monetary policy periods, the greater the weight given to the GSCI, the worse the return on all of the portfolios, with the small-cap and momentum portfolios being harmed the most; (2) in restrictive policy periods, the greater the weight given to the GSCI, the higher the return on all of the portfolios, with the growth and small-cap portfolios benefiting the most; and (3) in both expansive and restrictive policy periods, the greater the weight given to the GSCI, the lower the standard deviation of all of the portfolios, with similar decreases in risk across all styles.

Contrarian strategies. Wang and Yu (2004) examine short-horizon (one to eight weeks) contrarian strategies (buy past losers and sell past winners) for 24 actively traded commodity futures for the period July 1983 to June 2000. They find significant returns (16 percent annual) to this contrarian strategy over a one-week horizon. Furthermore, they show that the profitability of the strategy increased significantly (a return of almost 30 percent annually) when implemented with high-volume and low-open-interest contracts (the evidence that open interest is a significant predictor of future returns is consistent with Hong and Yogo 2010). Longer portfolio formation and/or holding periods did not prove to be profitable.

Momentum strategies. Shen, Szakmary, and Sharma (2007) and Miffre and Rallis (2007) examine the profitability of momentum strategies (buy past winners and sell past losers) and contrarian strategies (sell past winners and buy past losers) in commodity futures. These studies build on the work of Erb and Harvey (2006), who provide evidence of profitable momentum strategies in commodity futures.

Miffre and Rallis (2007) study 31 futures contracts from 1979 to September 2004 and allow for two alternative roll procedures. Like other studies, they vary the ranking periods for determining past winners and losers $(1,3,6$, $12,24,36$, and 60 months) and the holding periods for the resulting portfolios $(1,3,6,12,18,24,36$, and 60 months). The authors find that 13 momentum strategies were profitable in the sample period; these strategies earned an average annual return of 9.38 percent (in comparison, an equal-weighted, long-only portfolio of all contracts lost 2.64 percent per year). Furthermore, abnormal returns after risk adjustment (they applied a traditional three-factor asset-pricing model to control for risk) continued to be significant. Interestingly, however, the higher returns came with substantially higher standard deviations of returns. Nonetheless, the reward-to-risk ratios are above the S\&P 500's ratio. The authors also find strong support for the hypothesis that the momentum strategies buy backwardated contracts and sell contangoed contracts. Finding correlation coefficients between the momentum portfolios' returns and returns on the S\&P 500 and T-bonds to be close to zero, the authors conclude that momentum in commodity futures offers a tactical allocation strategy that adds return and lowers risk to stock and bond exposures. In contrast to Wang and Yu (2004), the authors find no support for the profitability of contrarian strategies in commodity futures. 
Shen et al. (2007) study momentum strategies in 28 contracts from their inception through 2003; the authors use the first-deferred contract on the roll and 10 different ranking periods (ranging from 1 to 60 months). Like Miffre and Rallis (2007), they find significant positive abnormal returns, but they also find that returns in the pre1981 period are higher than those in the post-1981 period. Additionally, the authors continue to find significant momentum returns when the holding period is restricted to only one month. Again like Miffre and Rallis (2007), the authors find that the momentum strategies have much higher standard deviations of return than the control portfolios but generally have higher Sharpe ratios than the S\&P 500.

Hong and Yogo (2010) also find momentum in commodity returns. In a novel finding, however, they show that aggregate open interest in commodity futures predicts high commodity returns (and low bond returns). They find this relationship even after controlling for past returns (i.e., momentum itself), the short rate, the yield spread, the basis, and hedging pressure.

Marshall, Cahan, and Cahan (2008) examine numerous quantitative "trend-following" trading strategies (such as momentum and reversal) for 15 commodities for 1984-2005. Their strategies do not generate profits on 14 of the 15 commodities after adjusting for data-snooping biases. Szakmary, Shen, and Sharma (2010) hypothesize that the conflicting conclusions of Marshall et al. versus conclusions of other momentum studies are the result of differing research designs, specifically that the prior studies use daily data and returns for a limited number of individual contracts rather than for portfolios of aggregated contracts. In reexamining trend-following strategies in a momentum study research design, they continue to find significant abnormal profits from momentum strategies.

Term structure and roll procedure. Mouakhar and Roberge (2010) study the roll return component of total return and examine whether the approach followed by most passive commodity indices can be improved upon (see also Ma et al. 1992 for a discussion of issues surrounding roll procedures). Because roll return can be positive (with backwardation) or negative (with contango), the authors strive to maximize roll profits and minimize roll losses by taking into account the curvature of the term structure of futures prices (see also Fuertes, Miffre, and Rallis 2010). They calculate the slope between all successive futures contracts (out to one-year maturity), where a positive (negative) slope corresponds to contango (backwardation). For their long-only portfolio, they roll into the deferred contract that provides the lowest slope (i.e., the most backwardated contract or the least contangoed contract).

To compare their approach with the standard approach of rolling into the next nearby contract regardless of the shape of the term structure, the authors use Bloomberg data for 10 contracts ( 3 energy contracts starting in 1994, 2 precious metals starting in 1994, 2 industrial metals starting in 1998, and 3 grains starting in 2000-all ending in April 2006). On average, the improvement in return from their strategy is 4.8 percent per year and the risk is lower. Although passive indices are generally long-only indices (i.e., they hold only long futures positions), the authors also test a short-only approach that rolls into short contract positions that have the highest slope. The short-only strategy provides benefits that are less consistent than those from the long-only approach: Four contracts provide better returns, four contracts provide almost identical returns, and two post significantly lower returns. Their findings suggest that most long-only rolls should, on average, be at least into contracts with five or more months to maturity.

Fuertes et al. (2010) also extend the work of Mouakhar and Roberge (2010), Miffre and Rallis (2007), and Shen et al. (2007) by examining the joint influence on returns of momentum strategies and backwardation/ contango in the term structure of futures prices. The authors examine 37 commodities from 1979 through January 2007 and check for robustness by applying various roll procedures and by varying the frequency of rebalancing and portfolio formation date. The authors carefully show that, although momentum strategies tend to be long backwardated contracts and short contangoed contracts (much like strategies using the term structure of futures prices), the two strategies (momentum and backwardation/contango) are not fully overlapping. The authors find that a strategy that combines the two approaches yields abnormal returns of approximately 20 percent per year. The strategy entails a risk level that is substantially higher, however, than the level for long-only passive benchmarks, but the reward-to-risk ratios are also substantially higher. In examining the correlations between their double-sort portfolios (i.e., sorted by momentum and backwardation/contango) and stock and bond returns, they find relatively low correlations, indicating that the double-sort strategies can mitigate bond and equity risk in much the same way that simple long-only exposure to commodities does. 
Hedging pressure. The hedging pressure hypothesis suggests that the net hedging needs of market participants - and, in some models, systematic risk (as measured by the covariance of futures returns with the market return) - determine futures risk premiums (or the shape of the term structure of futures prices). De Roon et al. (2000) test this hypothesis but add the cross-market hedging pressure from other, related futures markets to test whether this factor (cross-market hedging) is also an influence on returns. Studying data for the 1986-94 period, the authors examine 20 futures markets in four groups: financial, agricultural, mineral, and currency. The authors control for the influence of supply or demand shocks (as described in the discussion of the theory of storage) and find that own- and cross-hedging pressures explain futures returns. Furthermore, these variables also explain spot returns, which adds support for the hedging pressure hypothesis.

Storage. In its simplest form, the theory of storage predicts that supply-and-demand conditions (rather than hedging pressures) drive the term structure of forward prices. Fama and French (1988), using industrial metals contracts (aluminum, copper, lead, tin, and zinc) for 1972-1983 provide early support for the theory of storage. The authors note that the difficulty of obtaining direct data on storage to test the hypothesis that the marginal convenience yield declines as inventory levels increase requires a special empirical approach. They contend that a testable empirical implication of the theory is that futures prices vary less than spot prices when inventory is low and that the two prices have similar variability when inventory is high. To test this implication, the authors use the phase of the business cycle and the interest-adjusted (i.e., futures less spot) basis as a proxy for the level of inventory for industrial metals. Their evidence indicates that metal inventories fall with demand shocks at business cycle peaks, that forward prices are below spot prices, and that spot prices are more variable than forward prices - all as predicted by the theory of storage. Refining the work of Fama and French, Ng and Pirrong (1994) also find similar support for the theory of storage in metals prices (aluminum, copper, lead, zinc, and for contrast, a precious metal, silver) in the 1986-92 period.

Gorton et al. (2008) examine the relationship between actual physical inventories and futures risk premiums for 31 commodity futures for 1969-2006. The authors obtained measures of inventory for a sizable sample and link them to commodity futures risk premiums. The study's main findings are that a negative relationship exists between inventory levels and the futures basis and that excess returns to momentum and backwardation strategies derive from the level of inventories. That is, low (high) inventory levels are associated with a backwardated (contangoed) term structure of futures prices. Thus, the study finds support for the theory of storage rather than the hedging pressure theory.

Volatility. Chong and Miffre (2010) further explore the correlations between commodity futures and traditional asset classes. The authors use GARCH (generalized autoregressive conditional heteroscedasticity) volatility modeling to estimate dynamic conditional (conditioned on equity and interest rate volatility) correlations between 25 commodities and 13 traditional asset classes over the 1981-2006 period. 5 Their key findings indicate that (1) the conditional correlations between 19 of the 25 commodities and the S\&P 500 have fallen in a significant manner over time (especially for precious metals) and are close to zero or even negative; (2) the correlations between 11 commodity futures and the S\&P 500 fall (especially for precious metals and certain agricultural sectors but not for energy) when equity volatility increases; and (3) the correlations between T-bonds and commodity futures tend to rise as volatility in long-term fixed-income securities increases. Thus, the diversification benefits of commodities for equityholders have improved over time and are most prevalent when risk is highest in the equity markets.

Managed Futures. Although the majority of research evaluates commodity performance via long-only index funds, several studies examine the returns to managed futures. Edwards and Park (1996) and Edwards and Liew (1999) identify three broad classifications of managed futures investments: commodity pool operators, commodity trading advisers, and public futures funds. The authors note that the fees for all three classifications

5In a GARCH analysis, the "conditioning" variable is the volatility (hence, the term "conditional heteroscedasticity") of the underlying asset returns. In the simplest case, one might measure correlations conditional on, for example, whether volatility is above the long-run average versus whether it is below the long-run average. 
are generally quite high, with public funds having the highest fees and CTAs, the lowest. In spite of the high fees, the authors conclude that for the 1980s and 1990s, the performance of large portfolios of CTAs and CPOs compares favorably with that of the U.S. stock market. Furthermore, they find that these commodity portfolios garner a substantial allocation when used to supplement an optimal portfolio that consists of stocks and bonds. Finally, the authors note that their results are based on a large portfolio of CTAs (CPOs) that were rebalanced monthly, which is a strategy that would be extremely difficult for an investor to replicate. In addition, although the authors made several adjustments to correct for biases afflicting the databases they used, concerns remain regarding the influence of biases on the findings.

Jensen, Johnson, and Mercer (2002) compare the benefits of adding managed commodity futures with adding "unmanaged" (passive) commodity futures to diversified portfolios of traditional asset classes over the 1973-99 period. To avoid problems with database biases, the authors rely on the Mount Lucas Management (MLM) Index as a proxy for the returns to managed futures. ${ }^{6}$ The GSCI is used to proxy a passive investment in commodity futures. The authors show that higher Sharpe ratios are achieved by adding managed futures, rather than the GSCI, to portfolios that include U.S. stocks, international stocks (EAFE), U.S. corporate bonds, and T-bills.

The authors also provide a novel contribution by examining the influence of Fed monetary policy on the investment benefits of managed commodity futures. (Jensen, Johnson, and Mercer 2000 earlier investigated the influence of monetary policy on the benefits of passive futures but not managed futures.) The authors find that a simple buy-and-hold investment in the MLM Index beats a strategy of buying the GSCI when monetary policy is restrictive and not holding the GSCI when policy is expansive. When the authors examine the portfolio diversification benefits of the MLM versus the GSCI, after controlling for the Fed's monetary policy, they find that (1) the Sharpe ratios are higher in periods of both expansive and restrictive monetary policy for diversified portfolios that include the MLM rather than the GSCI and (2) for both the GSCI and the MLM, the increase in the Sharpe ratio when commodities are added is dramatically larger in restrictive policy phases. Although using the MLM in expansive policy periods offers some improvement, it is minimal.

Jensen, Johnson, and Mercer (2003) also use the MLM to examine the benefits of managed futures. Because investors typically limit investments in alternative assets to modest weights, the authors evaluate the benefits of adding a 10 percent MLM allocation to a portfolio of stocks, bonds, and T-bills at four alternative levels of overall portfolio standard deviation (ranging from conservative to aggressive). ${ }^{7}$ Their findings indicate that, even with this small (10 percent) allocation, portfolio Sharpe ratios increase significantly across the risk spectrum. Interestingly, the authors find the largest benefit is attributable to risk reduction and accrues to investors holding conservative portfolio allocations. They also find that tactically allocating 10 percent of the portfolio to the MLM in periods of expansive monetary policy provides no net benefit (i.e., Sharpe ratios are relatively unchanged). In contrast, a 10 percent allocation during periods of restrictive monetary policy produces substantial benefits; portfolio returns are made significantly higher and portfolio risk is significantly reduced.

Precious Metals. Because of their widely acknowledged reputation as a store and standard of value, precious metals-particularly, gold - have been the most popular commodities for investors to include in their investment portfolios. Investment professionals and academicians typically contend that precious metals, as an investment asset class, have three characteristics that provide unique portfolio benefits. Specifically, evidence shows that precious metals (1) provide a hedge against U.S. inflation, (2) provide a safe haven against economic turbulence and increased volatility in security markets, and (3) provide a hedge against the foreign exchange value of the U.S. dollar (since 1971, when the final link between the dollar and gold was broken).

6The MLM is a managed futures index that consists predominantly of commodities and uses a momentum-based algorithm to determine both long and short positions in futures contracts. An especially attractive feature of the MLM Index is that Mount Lucas Management offers a product that tracks the performance of the MLM Index, thus making the index an investable asset. Therefore, the MLM Index avoids the biases that plague other managed futures proxies.

7Jensen et al. (2002) did not constrain the weights allowed in either the GSCI or the MLM in optimized portfolios, nor did they present the weights. 
Jaffe (1989) and Chua, Sick, and Woodward (1990) present evidence that during the 1970s and 1980s, precious metals experienced favorable investment performance on both a stand-alone basis and as a portfolio component. Furthermore, Jaffe finds that adding a small gold exposure to a broadly diversified portfolio serves to enhance performance by lowering risk and increasing portfolio return.

Hillier, Draper, and Faff (2006) evaluate the relative investment merits of gold, silver, and platinum over the 1976-2004 period. They find that all three precious metals offer diversification benefits; gold, however, is shown to have the most attractive investment attributes. Furthermore, the major benefit of precious metals is shown to be their ability to hedge adverse market conditions, because precious metals perform best during periods of high market volatility. In spite of the identified association between precious metal performance and market volatility, the authors conclude that a strategic allocation to precious metals is superior to a tactical allocation guided by market variance.

Conover et al. (2009) extend the 2006 Hillier et al. study by evaluating the investment benefits of gold, silver, and platinum over the 1973-2006 period. Conover et al. find that a strategic allocation to precious metals serves to enhance portfolio performance. Furthermore, the benefit of adding a precious metal exposure via the equities of precious metal companies is superior to the benefit garnered from an exposure obtained via the physical precious metal commodity. For example, the authors show that allocating 25 percent of the total portfolio to precious metal equities increases the portfolio's annual return by 1.65 percentage points while reducing portfolio standard deviation by 1.86 percentage points. Finally, the authors show that using a tactical allocation approach that relies on shifts in Fed monetary policy to guide the allocation to precious metals offers a substantial incremental improvement. In particular, precious metals are shown to offer substantial portfolio benefits during periods of Fed tightening while offering virtually no portfolio benefit during periods of Fed easing.

Baur and McDermott (2010) examine whether gold has historically provided a safe haven from losses in global equity markets. They study stock indices from the G-7 countries, the BRIC countries, Australia, and Switzerlandall denominated in local currency — for the 1979-2009 period.8 Additionally, they examine regional indices and a world index, both denominated in U.S. dollars. They conclude that gold provides a "weak safe haven" ("strong safe haven”) against declines in a particular stock index if gold is uncorrelated (negatively correlated) with that index. The authors show that among the regional indices, gold is a strong safe haven for the North American region. They note that the positive correlation between gold returns and the other regions' stock returns is probably induced by their being denominated in U.S. dollars. For extreme market shocks (at the 1 percent quantile), however, negative correlations are found for the other regional indices. Using individual countries' indices, they find that gold is a strong safe haven for Canada, France, Germany, Italy, Switzerland, the United Kingdom, and the United States. Gold does not appear to provide a hedge against adverse conditions in emerging markets (the BRIC countries).

Dempster and Artigas (2010) examine the performance of gold as compared with the performance of traditional U.S. inflation hedges - specifically, the GSCI, two REIT indices, and TIPS (Treasury InflationProtected Securities) over the 1974-2009 period. The authors find that of these four potential inflation hedges, gold provided the greatest diversification benefit in the sample period when added to portfolios containing U.S. stocks, non-U.S. stocks, corporate bonds, and T-bonds. They note that the portfolio allocation in gold to attain the minimum-variance (optimized) portfolio ranges from 4 percent to 6.3 percent, while the allocation to attain the maximum reward-to-risk ratio ranges from 7 percent to 9.9 percent.

Capie, Mills, and Wood (2005) examine the efficacy of gold as a hedge against the foreign exchange value of the dollar. They examine the sterling-to-dollar and yen-to-dollar exchange rates in the 1971-2004 period and find that, although gold generally has been a hedge against a falling dollar, its efficacy has varied considerably.

${ }^{8}$ The G-7 consists of Canada, France, Germany, Italy, Japan, the United Kingdom, and the United States. The BRIC countries are Brazil, Russia, India, and China. 
Since the Fed's extraordinary easing following the subprime crisis of 2008-2009, many pundits in the popular press have been arguing that the only driver of gold's significant recent price increase is the foreign exchange value of the dollar (which has fallen considerably over this same period) and that inflation has little or nothing to do with it. After all, they argue, throughout much of 2009 and 2010 the Fed's main concern had been deflation, not inflation, whereas the dollar index moved almost perfectly in the opposite direction of gold. For example, a Wall Street Journal article (Opdyke 2010) cites research from Ibbotson Associates showing that over the past 30 years, the correlation between gold and the dollar has been -0.65 but the correlation between gold and U.S. inflation since 1978 has been 0.08 . Thus, Opdyke argues that gold is not a commodity—in the consumption sense-but is, rather, a currency.

In fairness, we note that other pundits are receiving equal space for arguing that the run-up in gold reflects higher anticipated inflation as well as the falling dollar.

\section{Recent Developments in the Market for Commodity Investments}

Two developments of particular note in the early part of the 21st century have to do with the boom and bust in commodity prices and with the introduction of ETFs and ETNs for base metals (i.e., not gold or silver).

"Speculation" and Commodity Price Bubbles. From late 2006 through early 2009, the world experienced an unprecedented and, to some extent, synchronized boom and bust in commodity prices. Index funds linked to the GSCI, for example, experienced returns of more than 100 percent between January 2007 and July 2008 and then experienced returns of approximately -75 percent between July 2008 and March 2009. Oil drew much of the attention; it moved from $\$ 65$ per barrel in June 2007 to $\$ 145$ in July 2008 and then retreated to $\$ 31$ in December 2008. Similar run-ups and run-downs occurred in numerous other commodities. As of late 2010, several commodities had again experienced sizable run-ups - cotton up 100 percent, silver up 72 percent, gold up 29 percent, copper up 21 percent, and oil increasing from $\$ 31$ in late 2008 to more than $\$ 100$ per barrel in 2010. Undoubtedly, among the factors driving these prices were increased demand for commodities from emerging economies, the fall in the U.S. dollar, concerns about the Fed's quantitative easing and future U.S. inflation, and perhaps, speculation-driven demand for commodity exposure.

These dramatic swings in prices have coincided with significant growth in commodity index trading. On the one hand, this heightened level of investment has been characterized as speculation by many, including policymakers in Washington, DC, and has been blamed for the synchronized bubbles (and subsequent busts) in commodity prices. On the other hand, the price swings were also occurring during substantial increases in world demand for commodities from China, India, and other emerging economies and a decrease in global economic activity following the housing and financial crisis that started in the United States.

Recently, studies have begun to examine the role of commodity index traders in these price swings. Irwin, Sanders, and Merrin (2009) note that the main thrust of the speculative bubble argument is that it was driven (up and down) by the sizable flows of money into and out of commodity investment vehicles (including derivatives), which, in turn, influenced commodity prices themselves. The authors contend, however, that the bubble argument "does not stand close scrutiny" (p. 377). They point out that the flow of money into futures and derivatives markets is not "demand" and that money flows should not affect futures prices because new positions can be created at any price level. Furthermore, they argue that flows into derivatives do not influence spot prices in a significant enough manner to move them away from levels supported by supply-and-demand fundamentals. Additionally, the new commodity index entrants are entering these markets not as advantaged speculators trading against naive hedgers but more simply as participants trading against sophisticated commercial firms that are quite possibly advantaged regarding information about future commodity prices and supply-and-demand factors. The authors also note several empirical facts that are inconsistent with the bubble argument and show that position changes by traders did not cause ("Granger-cause") futures price movements. 9

${ }^{9} \mathrm{~A}$ time series is said to Granger-cause another time series if the first is useful in predicting the second but the second is not useful in predicting the first. Thus, there is a temporal ordering from the first series to the second. 
Stoll and Whaley (2010) provide a comprehensive study of whether commodity index investing is, in their words, "a disruptive force" in commodity futures markets, and they reach conclusions that are similar to those of Irwin et al. (2009). Briefly, Stoll and Whaley conclude that to characterize commodity index investing as speculation is wrong. They show that flows of money into and out of commodity index investment vehicles do not cause price changes in commodity futures.

This view is consistent with the conclusions of a recent report prepared by the Organisation for Economic Co-Operation and Development ("Speculation and Financial Fund Activity: Draft Report," May 2010) that states:

[This study] provides a detailed statistical and econometric analysis of the effects of the participation of financial funds - index and swap - in agricultural commodity futures markets as well as for crude oil. The results indicate that the use of financial instruments such as index/swap funds, although important in size, do not affect market returns in most markets and indeed the larger long positions of these funds lead to lower market volatility in a Granger sense. (p. 2)

Tang and Xiong (2010) note that the potential diversification (and other) benefits of commodities futures began to be better known beginning in about 2000, which naturally led to a substantial increase in investments in various instruments linked to commodity indices. This increasing participation of index investors led to a process of financialization among commodity markets. Consequently, prices across various commodities became more highly correlated and commodity prices in general became more correlated with those of other financial assets. The authors find evidence consistent with this observation and also find that the increases in correlations between commodities in the two most significant commodity indices (the GSCI and the DJ-UBSCI) were more pronounced than the correlations between commodities not in these indices. Additionally, these correlation changes preceded the financial crisis. Thus, the authors argue that the financialization process (i.e., speculation) causes price movements whereas supply-and-demand influences play a lesser role. What is not addressed by their study is how the changes in correlations (which were caused by financialization) led to the boom and bust in commodity prices between 2006 and 2009.

ETFs and ETNs of Physical Metals. ETFs backed by physical holdings of gold and silver have existed for some time, but the introduction of ETFs and ETNs for physical base metals is recent. For example, both iShares and JPMorgan have recently filed with the U.S. SEC to offer physical copper ETFs. Some physical ETFs already in place are ETF Securities' Platinum Shares (ticker PPLT) and Palladium Shares (ticker PALL).

We are unaware of published studies examining the influence of these new physical ETFs and ETNs on spot prices, but casual empiricism and much popular sentiment in the investment community suggest the presence of an influence. For example, many analysts argue that the markets face a very real risk of hoarding. Concerns about physical shortages (because of, say, temporary supply disruptions) might become self-fulfilling as demand for ETF exposure causes additional buying of the physical commodities to back the ETFs (generally not a concern for gold or silver). In 2008, widespread concern arose regarding a supply disruption in rice that resulted in mass hoarding of rice around the globe and panic buying that almost doubled rice prices. How might the presence of physical rice ETFs have played into that situation? For those who argue that ETFs backed by futures contracts can also demand physical delivery via the long contract positions, the reality is that few contracts are carried through to maturity and delivery, and furthermore, a time lag occurs between required physical delivery and maturity of a contract.

Although the United States Natural Gas Fund LP ETN (ticker UNG) is not a physical commodity ETN, it recently revealed that it controls close to 20 percent of the benchmark natural gas futures contracts. Before it made the decision to issue no new shares, it was trading at a 16 percent premium to its net asset value, indicating that investors were paying a sizable premium just to gain exposure to natural gas via this liquid ETN. Because the ETN's return objective is simply to mimic the return on the nearby NYMEX natural gas futures contract, one could consider this premium irrational for investors capable of trading the futures contract themselves. Thus, in this case, the desire for exposure ("speculation") may be driving pricing.

This publication qualifies for $1 \mathrm{CE}$ credit. 


\section{Bibliography}

Ankrim, Ernest M., and Chris R. Hensel. 1993. "Commodities in Asset Allocation: A Real-Asset Alternative to Real Estate?” Financial Analysts Journal, vol. 49, no. 3 (May/June):20-29.

The authors use the GSCI and Intermarket Management's Investable Commodity Index to examine the performance of commodity futures during the 1972-90 period. The authors find that commodities offered superior risk-adjusted performance during the 1970s and inferior performance during the 1980s. For the entire 19-year period, the risk-adjusted performance was superior to both stocks (S\&P 500) and bonds (Ibbotson U.S. Intermediate-Term Government Bond Index). Furthermore, they show that commodities have low correlations with both stocks and bonds, which supports the diversification potential of commodities. The authors conclude that pension fund managers should consider adding a commodity exposure to their portfolios. They suggest that commodities offer an attractive real asset alternative for investors wishing to avoid the illiquidity of real estate.

Anson, Mark J.P. 1999. "Maximizing Utility with Commodity Futures Diversification." Journal of Portfolio Management, vol. 25, no. 4 (Summer):86-94.

Anson finds that an investment in a commodity futures index offers diversification benefits for investors holding portfolios composed of traditional asset classes (stocks and bonds). Furthermore, he shows that the benefits of commodity futures are positively related to an investor's degree of risk aversion. He claims that commodity futures offer diversification benefits because of their significant positive correlation with the rate of inflation and changes in the rate of inflation, as shown in previous research.

Baur, Dirk G., and Thomas K. McDermott. 2010. “Is Gold a Safe Haven? International Evidence.” Journal of Banking E Finance, vol. 34, no. 8 (August):1886-1898.

"The aim of this paper is to examine the role of gold in the global financial system. We test the hypothesis that gold represents a safe haven against stocks of major emerging and developing countries. A descriptive and econometric analysis for a sample spanning a 30-year period from 1979 to 2009 shows that gold is both a hedge and a safe haven for major European stock markets and the United States but not for Australia, Canada, Japan, and large emerging markets such as the BRIC countries. We also distinguish between a weak and strong form of the safe haven and argue that gold may act as a stabilizing force for the financial system by reducing losses in the face of extreme negative market shocks. Looking at specific crisis periods, we find that gold was a strong safe haven for most developed markets during the peak of the recent financial crisis." (p. 1886)

Bjornson, Bruce, and Colin A. Carter. 1997. "New Evidence on Agricultural Commodity Return Performance under Time-Varying Risk.” American Journal of Agricultural Economics, vol. 79, no. 3 (August):918-930.

The authors examine the relationship between the returns to eight agricultural commodity futures contracts and several macroeconomic variables. The authors use monthly returns over the period August 1969 through December 1994. They find that agricultural commodities perform best when interest rates, inflation, and economic growth are relatively low. They conclude that agricultural commodities provide a natural hedge against business cycles. 
Bodie, Zvi. 1983. "Commodity Futures as a Hedge against Inflation.” Journal of Portfolio Management, vol. 9, no. 3 (Spring):12-17.

The author evaluates the benefit of adding an equally weighted portfolio of commodity futures to a portfolio composed of stocks, T-bills, and T-bonds. He uses correlations measured over the 1953-81 period, together with realistic assumptions about the four asset classes, to derive the mean-varianceefficient frontier. He finds that supplementing the traditional portfolios with a commodity exposure results in a significant upward shift in the efficient frontier. The improved portfolio performance is attributed to the positive influence that inflation has on commodities, which contrasts with its negative effect on the other asset classes.

Booth, David G., and Eugene F. Fama. 1992. "Diversification Returns and Asset Contributions.” Financial Analysts Journal, vol. 48, no. 3 (May/June):26-32.

"For a portfolio with a constant percentage invested in each asset, the compound return is the sum of the contributions of the individual assets in the portfolio. The portfolio compound return is greater than the weighted average of the compound returns on the assets in the portfolio. The incremental return is due to diversification. The contribution of each asset exceeds its compound return by the amount it adds to the portfolio diversification return.

The compound return on an asset is approximately the asset's average return minus one-half the asset's variance. A portfolio's average return is the weighted average of each asset's average return, but a portfolio's variance is the weighted average of each asset's covariance. It follows that the return contribution of an asset can be better approximated by subtracting one-half the covariance than onehalf the variance." (p. 26)

Capie, Forrest, Terence C. Mills, and Geoffrey Wood. 2005. "Gold as a Hedge against the Dollar." Journal of International Markets, Institutions and Money, vol. 15, no. 4 (October):343-352.

"The extent to which gold has acted as an exchange rate hedge is assessed using weekly data for the last thirty years on the gold price and sterling-dollar and yen-dollar exchange rates. A negative, typically inelastic, relationship is indeed found between gold and these exchange rates, but the strength of this relationship has shifted over time. Thus, although gold has served as a hedge against fluctuations in the foreign exchange value of the dollar, it has only done so to a degree that seems highly dependent on unpredictable political attitudes and events." (p. 343)

Carpenter, Claudia. 2010. "SPDR Gold Leads Growth in Commodity Products, BlackRock Reports." Bloomberg BusinessWeek (14 May).

Carpenter references statistics (provided by BlackRock) documenting the tremendous growth that has occurred in commodity-linked exchange-traded products and funds. The growth in commodity investment is linked to the nine consecutive years of advance in gold prices and the accompanying growth in gold-based investment products.

Chong, James, and Joelle Miffre. 2010. "Conditional Correlation and Volatility in Commodity Futures and Traditional Asset Markets." Journal of Alternative Investments, vol. 12, no. 3 (Winter):61-75.

"The impressive rise in commodity prices since 2002 and their subsequent fall since July 2008 have revived the debate on the role of commodities in the strategic and tactical asset allocation process. Commonly accepted benefits include the equity-like return of commodity indices, the role of commodity futures as risk diversifiers, and their high potential for alpha generation through longshort dynamic trading. This article examines conditional correlations between various commodity futures with stock and fixed-income indices. Conditional correlations with equity returns fell over time, which indicates that commodity futures have become better tools for strategic asset allocation. 
The correlations between the S\&P 500 Index and several commodities also fell in periods of aboveaverage volatility in equity markets. This is desirable for long institutional investors as they need the benefits of diversification most in periods of high volatility in equity markets. Similarly, the results suggest that adding commodity futures to T-bill portfolios reduces risk further in volatile interest rate environments." (p. 61)

Chua, Jess H., Gordon Sick, and Richard S. Woodward. 1990. "Diversifying with Gold Stocks." Financial Analysts Journal, vol. 46, no. 4 (July/August):76-79.

The authors extend Jaffe's (1989) study by examining the relative investment benefits of investing in gold equities versus gold bullion during the period September 1971 through December 1988. By splitting their sample period into two subperiods, the authors show that the diversification benefits of gold bullion are much more consistent than the diversification benefits of gold equities. In particular, they find that the beta of gold equities more than doubled between the 1970s and 1980s, whereas the beta of gold bullion remained largely unchanged at approximately zero in both periods. Thus, the authors question the diversification benefits of gold equities, particularly over short investment horizons.

Conover, C. Mitchell, Gerald R. Jensen, Robert R. Johnson, and Jeffrey M. Mercer. 2009. "Can Precious Metals Make Your Portfolio Shine?” Journal of Investing, vol. 18, no. 1 (Spring):75-86.

The study extends the results of earlier research that investigated the benefits of investing in gold, silver, and platinum. The authors address two major investor concerns: (1) What are the benefits of investing in precious metals? (2) How can investors best achieve an exposure to precious metals? Their findings suggest that precious metals serve as an effective hedge against the typical decline in equities that occurs during an increasing-interest-rate environment. And to best capture the benefit of precious metals, investors should allocate a prominent percentage of their portfolio to the equities of precious metal companies. For example, allocating 25 percent of a U.S. equity investor's portfolio to precious metal equities increases annual returns by 1.65 percent and reduces the portfolio's standard deviation by 1.86 percent. Smaller allocations to precious metals improve portfolio performance but to a lesser degree. The investment benefits are considerably larger if the exposure to precious metals is obtained indirectly via an investment in the equities of precious metal companies rather than directly by purchasing the precious metal (e.g., gold bullion) as a commodity. During periods of Fed tightening (when interest rates increase), the returns to precious metal commodities have been significantly higher than during expansive policy periods (when interest rates decrease), which is in stark contrast to the U.S. equity market and the equities of precious metal companies. Both direct and indirect investments in precious metals have provided significant return and risk benefits to U.S. equity portfolios during periods of Fed tightening, which represented 45 percent of the sample period. In contrast, neither direct nor indirect investments in precious metals have provided benefits of much consequence when the Fed is easing.

(Fall):10-19.

The authors find that a commodity futures allocation greater than 5 percent is required to achieve a significant reduction in the risk of an equity portfolio. Furthermore, the authors find that an allocation to commodities enhances portfolio return, in addition to reducing risk, during periods of restrictive Fed policy. In contrast, during periods of expansive Fed policy, portfolio returns are less when commodity futures are added but portfolio risk is still reduced. In other words, they find that the benefits of commodity futures are most pronounced when the Fed is raising interest rates. The authors argue that periods when Fed policy is restrictive correspond to periods of heightened inflationary concerns for investors; thus, they contend, their findings support the view that commodities act as an inflation hedge. The authors show that the use of a tactical allocation approach that relies on Fed policy shifts is superior to both a strategic allocation to commodity futures and an all-equity portfolio. Finally, the authors find that the benefits of commodity investments are comparable for equity investors regardless of their investment style. 
de Roon, Frans A., Theo E. Nijman, and Chris Veld. 2000. "Hedging Pressure Effects in Futures Markets." Journal of Finance, vol. 55, no. 3 (June):1437-1456.

"We present a simple model implying that futures risk premia depend on both own-market and crossmarket hedging pressures. Empirical evidence from 20 futures markets, divided into four groups (financial, agricultural, mineral, and currency) indicate that, after controlling for systematic risk, both the futures own hedging pressure and cross-hedging pressures from within the group significantly affect futures returns. These effects remain significant after controlling for a measure of price pressure. Finally, we show that hedging pressure also contains explanatory power for returns on the underlying asset, as predicted by the model." (p. 1437)

Dempster, Natalie, and Juan Carlos Artigas. 2010. "Gold: Inflation Hedge and Long-Term Strategic Asset." Journal of Wealth Management, vol. 13, no. 2 (Fall):69-75.

"Will today's solution become tomorrow's problem? An increasing number of investors are becoming wary about the outlook for price stability. What if central banks leave interest rates too low for too long or pump too much money into the economy? If they do, they risk making today's solution into tomorrow's problem: a sharp rise in inflation. If inflation does materialize, then traditional inflation hedges, such as gold, commodities, real estate, and inflation-linked bonds, are likely to outperform other mainstream financial assets. Gold has a long history as an inflation hedge: In the eight years between 1974 and 2008 when U.S. inflation was high (defined as CPI inflation exceeding 5\%) gold rose by an average of $14.9 \%$ in real terms, outperforming other assets such as bonds, equities, and even other commodities. Still, some investors may be reluctant to add an asset intended to function primarily as an inflation hedge to their portfolio at this stage, as there are currently equally compelling reasons for inflation to remain low. This leads the authors to ask whether any of the four traditional inflation hedges can demonstrably enhance investors' risk-adjusted returns even in a low-to-moderate inflation environment. Real returns are not, after all, the only means of assessing portfolio performance. The volatility of an asset's returns and its interaction with other assets are also important. The authors also examine how gold has performed relative to the other three traditional inflation hedges, both individually and collectively, using a portfolio optimizer. They then explore whether a strategic case can be made for gold in the portfolio of an investor that already holds TIPS (inflation-linked bonds).” (p. 7)

Dusak, Katherine. 1973. "Futures Trading and Investor Returns: An Investigation of Commodity Market Risk Premiums." Journal of Political Economy, vol. 81, no. 6 (November/December):1387-1406.

"The long-standing controversy over whether speculators in a futures market earn a risk premium is analyzed within the context of the capital asset pricing model recently developed by Sharpe, Lintner, and others. Under that approach the risk premium required on a futures contract should depend not on the variability of prices but on the extent to which the variations in prices are systematically related to variations in the return on total wealth. The systematic risk was estimated for a sample of wheat, corn, and soybean futures contracts over the period 1952 to 1967 and found to be close to zero in all three cases. Average realized holding period returns on the contracts over the same period were close to zero." (p. 1387)

Edwards, Franklin R., and Jimmy Liew. 1999. "Managed Commodity Futures." Journal of Futures Markets, vol. 19 , no. 4 (June):377-411.

The authors examine the performance of managed commodity futures as represented by public commodity funds, commodity pool operators, and commodity trading advisers. The authors indicate that the costs associated with investing in CPOs and CTAs may be quite large because the funds may incur significant transaction costs, which are added to a number of fees charged to investors, including management fees, profit-based incentive fees, and loads. Despite these relatively high costs, the authors find that the net return to commodity fund investments is frequently relatively attractive. Each 
individual fund, however, has relatively volatile returns, so the stand-alone performance of managed commodity futures is poor relative to traditional investments. The authors find that, in general, adding a portfolio of CPOs or CTAs to a traditional investment portfolio enhances portfolio performance. In addition, the authors compare the returns to CTAs and CPOs with the returns to the passive Reuters/Jefferies CRB Index and the MLM. The MLM is a dynamic index based on momentum in commodity prices, which is consistent with the strategy followed by many managed futures funds. The authors find a significant positive relationship between the returns to managed futures and the MLM but no significant relationship between managed funds and the CRB. This finding is consistent with the contention that the MLM provides a general indicator of the performance of managed futures. The authors also find, however, that neither the MLM nor the CRB supplants managed futures in their derived efficient portfolios.

Edwards, Franklin R., and James M. Park. 1996. “Do Managed Futures Make Good Investments?” Journal of Futures Markets, vol. 16, no. 5 (June):475-517.

The authors evaluate the performance of managed futures during the 1983-92 period. Three different forms of managed futures are examined: commodity trading advisers, commodity pool operators, and public futures funds. The performance and fee structures for the alternative investment vehicles are presented. The authors obtained the managed-futures return data from proprietary databases, which collect voluntary performance reports from participants. In this study, CTAs show the best performance, followed by CPOs; public funds fall a distant third. The authors attribute the superior performance of CTAs to their relatively low fees and attribute the poor performance of public funds to their high fees. CTAs and CPOs also show superior performance to a passive strategy that buys and holds a futures index. The authors find considerable variation in the performance of managed futures in the sample period. Finally, annual returns for managed futures are shown to have a relatively high correlation with inflation, which provides support for the inflation-hedging potential of managed futures.

Erb, Claude B., and Campbell R. Harvey. 2006. "The Strategic and Tactical Value of Commodity Futures." Financial Analysts Journal, vol. 62, no. 2 (March/April):69-97.

The authors note that previous research indicates that the returns to commodity futures have been comparable to equity returns. They caution about extrapolating from these results. In particular, they report the following features of commodity returns that raise questions about the validity of blindly projecting future commodity performance from historical performance. (1) The historical performance of commodities is driven by a relatively few commodities that performed extremely well. (2) Commodity returns have subsided substantially over time. (3) The average equal-weighted excess return across individual commodities is negative. (4) The return to commodity portfolios is mostly the result of diversification return, which is attributable primarily to the process of rebalancing among commodities with low correlations and relatively high volatility. (5) Commodities have a relatively low and inconsistent relationship with inflation, which provides little support for their effectiveness as an inflation hedge.

Although the authors raise several issues regarding the benefits of including a strategic allocation to commodities, they find promising results for two tactical allocation approaches. Specifically, an approach based on momentum in commodity prices and an approach based on the term structure of commodity prices are both superior to a passive investment in commodities. Again, the authors caution that the underlying dynamics of the tactical approaches must continue for the approaches to have future viability. 
Fama, Eugene F., and Kenneth R. French. 1987. "Commodity Futures Prices: Some Evidence on Forecast Power, Premiums, and the Theory of Storage.” Journal of Business, vol. 60, no. 1 (January):55-73.

The authors contrast two theories of commodity futures: (1) Kaldor's (1939) "convenience yield" (which the authors rephrase in the language of the "theory of storage") and (2) the view, associated with Keynes (1930), which they describe in modern terms, that "a futures price [is split] into an expected risk premium and a forecast of the future spot price" (p. 55). Their empirical research produces results that are inconclusive. The authors argue, however, that their evidence leans toward the theory of storage: They write that ". . . statistical tests make the response of futures prices to storage-cost variables easier to detect than evidence that futures prices contain premiums or power to forecast spot prices" (p. 55). Thus, the authors find that either hypothesis could be valid or the correct explanation could contain elements of both. [Adapted from Laurence B. Siegel, "The Commodity Risk Premium: An Annotated Bibliography," unpublished (2006).]

—. 1988. "Business Cycles and the Behavior of Metals Prices." Journal of Finance, vol. 43, no. 5 (December):1075-1093.

"The theory of storage says that the marginal convenience yield on inventory falls at a decreasing rate as inventory increases. The authors test this hypothesis by examining the relative variation of spot and futures prices for metals. As the hypothesis implies, futures prices are less variable than spot prices when inventory is low, but spot and futures prices have similar variability when inventory is high. The theory of storage also explains inversions of 'normal' futures-spot price relationships around businesscycle peaks. Positive demand shocks around peaks reduce metal inventories and, as the theory predicts, generate large convenience yields and price inversions." (p. 1075)

Fuertes, Ana-Maria, Joelle Miffre, and Georgios Rallis. 2010. "Tactical Allocation in Commodity Futures Markets: Combining Momentum and Term Structure Signals.” Journal of Banking E Finance, vol. 34, no. 10 (October):2530-2548.

"This paper examines the combined role of momentum and term structure signals for the design of profitable trading strategies in commodity futures markets. With significant annualized alphas of 10.14 percent and 12.66 percent, respectively, the momentum and term-structure strategies appear profitable when implemented individually. With an abnormal return of 21.012 percent, our doublesort strategy that exploits both momentum and term-structure signals clearly outperforms the singlesort strategies. This double-sort strategy can additionally be utilized as a portfolio diversification tool. The abnormal performance of the combined portfolios cannot be explained by a lack of liquidity, data mining or transactions costs." (p. 2530)

Gorton, Gary, and K. Geert Rouwenhorst. 2006a. "Facts and Fantasies about Commodity Futures." Financial Analysts Journal, vol. 62, no. 2 (March/April):47-68.

The authors evaluate the performance of an equally weighted index of commodity futures for the period July 1959 through December 2004. Over this period, they find that the commodity index produced returns comparable to equities but had less variability. In addition, the commodity index exhibited positive skewness, a positive correlation with inflation, and a low correlation with stocks and bonds; these features are attractive investment characteristics. Finally, the authors find evidence counter to the contention that the equities of commodity-based companies can serve as substitutes for commodity futures. Specifically, commodity-based equities are shown to have a much higher correlation with the stock market than with commodity futures. 
2006b. “A Note on Erb and Harvey (2005).” Working Paper \#06-02, Yale International Center for Finance (January): http://icfpub.som.yale.edu/system/fileuploads/2595/original/06-02.pdf?1265650094.

This note indicates that the "diversification return" found by Booth and Fama (1992) and used to bolster the arguments of Erb and Harvey (2006) has no economic content and is, instead, simply a mathematical property arising from the way returns are calculated. Specifically, the authors say that the diversification return is the difference between the geometric return on a portfolio and the geometric return of its constituents and is related to the well-known difference between the arithmetic and geometric returns on the same portfolio. So, it should be counted as part of the return on the commodity index they have constructed, and if that return is higher than the riskless rate, that difference should be interpreted as a risk premium. [Adapted from Laurence B. Siegel, "The Commodity Risk Premium: An Annotated Bibliography," unpublished (2006).]

Gorton, Gary B., Fumio Hayashi, and K. Geert Rouwenhorst. 2008. "The Fundamentals of Commodity Returns.” Working paper, Yale University.

"Commodity futures risk premiums vary across commodities and over time depending on the level of physical inventories, as predicted by the theory of storage. Using a comprehensive dataset on 31 commodity futures and physical inventories between 1969 and 2006, we show that the convenience yield has a decreasing, nonlinear relationship with inventories. Price measures, such as the futures basis ('backwardation'), prior futures returns, and prior spot returns reflect the state of inventories and are informative about commodity futures risk premiums. The excess returns to Spot and Futures Momentum and Backwardation strategies stem in part from the selection of commodities when inventories are low. Positions of futures markets participants are correlated with prices and inventory signals, but we reject the Keynesian (1930) 'hedging pressure' hypothesis that these positions are an important determinant of risk premiums." (p. 1)

Greer, Robert J. 2000. "The Nature of Commodity Index Returns.” Journal of Alternative Investments, vol. 3, no. 1 (Summer):45-52.

The author evaluates the performance of the Chase Physical Commodity Index (CPCI) over the 1970-99 period. He concludes that the returns to the CPCI are comparable in size and volatility to those of the U.S. equity market. He finds that the benefits of commodities can be largely attributed to their strong positive correlation with inflation and unexpected inflation, whereas equities and bonds are negatively correlated with inflation.

Halpern, Philip, and Randy Warsager. 1998. "The Performance of Energy and Non-Energy Based Commodity Investment Vehicles in Periods of Inflation.” Journal of Alternative Investments, vol. 1, no. 1 (Summer):75-81.

For the 1974-96 period, the authors find that commodity-based futures contracts performed substantially better during periods of relatively high inflationary pressures than in periods of low inflation. Energy-based commodities (J.P. Morgan Energy Index) performed especially well during periods when inflation and unexpected inflation were unusually high. In contrast, equities, real estate, and bonds performed much better in low-inflation environments than they did in high-inflation environments. The authors conclude that energy futures contracts offer compelling opportunities during periods of increasing inflationary pressures.

Hillier, David, Paul Draper, and Robert Faff. 2006. “Do Precious Metals Shine? An Investment Perspective.” Financial Analysts Journal, vol. 62, no. 2 (March/April):98-106.

The authors examine the investment benefits of gold, silver, and platinum over the 1976-2004 period. All three precious metal commodities are shown to offer diversification benefits within a portfolio, with gold offering the greatest benefit. The optimal allocation to gold is shown to range from 9.5 percent for a portfolio composed of international stock indices to 30 percent for a portfolio of the 
S\&P 500. Finally, the authors show that a major benefit of precious metals is realized during periods of high market volatility. The authors conclude, however, that a strategic allocation to precious metals dominates a tactical allocation approach guided by market volatility.

Hong, Harrison, and Motohiro Yogo. 2010. “Commodity Market Interest and Asset Return Predictability." Working paper, Princeton University.

"We establish several new findings on the relationship between open interest in commodity markets and asset returns. High commodity market activity, as measured by high open-interest growth, predicts high commodity returns and low bond returns. Open-interest growth is a more powerful and robust predictor of commodity returns than other known predictors such as the short rate, the yield spread, the basis, and hedging pressure. Although positively correlated with commodity returns, open-interest growth contains information for future asset returns beyond contemporaneous commodity prices. Open-interest growth also predicts changes in inflation and inflation expectations. These findings suggest that open-interest growth contains information about future inflation that gets priced into commodity and bond markets with delay. Our findings are consistent with recent theories of gradual information diffusion and have implications for macroeconomics forecasting models." (p. 1)

Irwin, Scott H., Dwight R. Sanders, and Robert P. Merrin. 2009. "Devil or Angel? The Role of Speculation in the Recent Commodity Price Boom." Journal of Agricultural and Applied Economics, vol. 41, no. 2 (August):377-391.

"It is commonly asserted that speculative buying by index funds in commodity futures and over-thecounter derivatives markets created a 'bubble' in commodity prices, with the result that prices, and crude oil prices, in particular, far exceeded fundamental values at the peak. The purpose of this paper is to show that the bubble argument simply does not withstand close scrutiny. Four main points are explored. First, the arguments of bubble proponents are conceptually flawed and reflect fundamental and basic misunderstandings of how commodity futures markets actually work. Second, a number of facts about the situation in commodity markets are inconsistent with the existence of a substantial bubble in commodity prices. Third, available statistical evidence does not indicate that positions for any group in commodity futures markets, including long-only index funds, consistently lead futures price changes. Fourth, there is a historical pattern of attacks on speculation during periods of extreme market volatility." (p. 377)

Jaffe, Jeffrey F. 1989. "Gold and Gold Stocks as Investments for Institutional Portfolios." Financial Analysts Journal, vol. 45, no. 2 (March/April):53-59.

The author examines the relative performance of gold and silver investments and the benefits of adding gold investments to a broadly diversified portfolio. The study covers the period of September 1971 through June 1987. During the study period, gold, silver, and gold equities reported the highest returns but also had the highest standard deviations. In addition, these precious metals exhibited very low correlations with other asset classes (U.S. and foreign equities, U.S. corporate and government bonds, and real estate). Finally, the authors show that adding a small gold exposure to four broadly diversified portfolios results in an improvement in performance (lower risk and higher return) for each portfolio.

Jensen, Gerald R., Robert R. Johnson, and Jeffrey M. Mercer. 2000. "Efficient Use of Commodity Futures in Diversified Portfolios.” Journal of Futures Markets, vol. 20, no. 5 (May):489-506.

Using a broad array of asset classes, the authors find that mean-variance optimization produces a significant allocation to commodity futures. Specifically, the authors derive efficient portfolios for eight risk levels and find that the allocation to commodity futures exceeds 10 percent for all but the lowest risk portfolio. The authors then separate the sample period into periods of expansive versus restrictive Fed monetary policy. They argue that periods of restrictive Fed policy correspond to the 
Fed raising policy rates and represent periods of heightened inflationary pressures. The findings indicate that commodity futures have a substantial allocation in efficient portfolios during periods of restrictive Fed policy (periods of heightened inflationary pressures), whereas the allocation to commodity futures in efficient portfolios is minimal when monetary conditions are expansive. The authors conclude that their findings support the benefits of commodities as inflation-hedging instruments.

2002. "Tactical Asset Allocation and Commodity Futures." Journal of Portfolio Management, vol. 28, no. 4 (Summer):100-111.

"In this article the authors examine the diversification benefits of adding managed and unmanaged commodity futures to a traditional portfolio that consists of U.S. equities, foreign equities, corporate bonds, and Treasury bills from 1973 through 1999. Consistent with previous evidence, they find that commodity futures substantially enhance portfolio performance for investors, and managed futures provide the greatest benefit. They show that the benefits of adding commodity futures (both managed and unmanaged) accrue almost exclusively when the Federal Reserve is following a restrictive monetary policy. The results suggest that metals and agricultural futures contracts offer the most diversification benefits for investors. Overall, the findings indicate that investors should gauge monetary conditions to determine the optimal allocation of commodity futures within a portfolio, and whether a short or a long position should be established in a particular type of contract." (p. 100)

2003. "Time Variation in the Benefits of Managed Futures." Journal of Alternative Investments, vol. 5, no. 4 (Spring):41-50.

The authors evaluate the benefits of adding managed futures to traditional diversified portfolios during the 1961-2000 period. The authors rely on the MLM as a proxy for the return to managed futures. The MLM consists predominantly of commodities and uses a momentum-based algorithm to determine both long and short positions in futures contracts. The authors consider four portfolio allocations ranging from conservative to aggressive. To make their results more applicable for investors, the authors limit the futures allocation to 10 percent of the portfolio weight. Their findings indicate that an allocation to managed futures increases Sharpe ratios significantly for all four portfolio allocations, with the largest benefit accruing to the most conservative portfolio. The largest benefit is shown to come from risk reduction as opposed to return enhancement. Finally, the authors show that the benefits of adding managed futures accrue during periods of restrictive Fed monetary policy, which, the authors argue, align with periods of heightened inflationary pressures. During expansive Fed policy periods, the benefits of adding managed futures are trivial. The authors conclude that managed futures can be used most effectively if their allocation is guided by Fed monetary policy shifts.

Jensen, Gerald R., Jeffrey M. Mercer, and Robert R. Johnson. 1996. "Business Conditions, Monetary Policy, and Expected Security Returns.” Journal of Financial Economics, vol. 40, no. 2 (February):213-237.

"We examine the evidence that expected security returns can be forecasted by the term premium, default premium, and dividend yield, in light of recent findings that similar security return patterns are associated with Federal Reserve monetary policy developments. We extend Fama and French's (1989) analysis by suggesting that the monetary environment influences investors' required returns, and hence, the robustness of the models they propose. Our findings indicate that Fama and French's results vary dramatically across monetary environments; that is, the behavior of the businessconditions proxies and their influence on expected security returns is significantly affected by the monetary sector." (p. 213) 
Kaldor, Nicholas. 1939. "Speculation and Economic Stability." Review of Economic Studies, vol. 7, no. 1 (October):1-27.

Kaldor questions Keynes' (1930) conclusion that normal backwardation is caused by an imbalance in favor of short hedgers. He observes that the holder of a physical commodity receives a benefit that the holder of a forward contract (equivalently, a futures contract) does not. This benefit is the "possibility of making use of [the commodities] the moment they are wanted" (p. 6) - that is, the option to consume the commodity now. This option is valuable for the following reason: Suppose someone does not physically hold the commodity but wishes to consume it or use it in a productive process. That person faces search costs, including uncertainty surrounding the availability, price, and quality of the commodity. Kaldor refers to this benefit, forgone by futures holders, as the "convenience yield," and this nomenclature has stuck. Because of the existence of convenience yield, Kaldor argues that backwardation should be observed even in the absence of an imbalance in favor of short hedgers. Thus, normal backwardation is not purely a risk premium, as Keynes argued. At some level of imbalance in favor of long hedgers, however, the negative risk premium is larger than the convenience yield and one should observe the market in contango. [Adapted from Laurence B. Siegel, "The Commodity Risk Premium: An Annotated Bibliography," unpublished (2006).]

Kat, Harry M., and Roel C.A. Oomen. 2007a. "What Every Investor Should Know about Commodities, Part I: Univariate Return Analysis." Journal of Investment Management, vol. 5, no. 1 (First Quarter):4-28.

The authors evaluate the return distribution properties of 42 commodity futures over the period January 1965 through February 2005. By examining both monthly and daily returns, the authors produce several findings. The average return on individual commodity futures contracts does not differ significantly from zero; energy contracts, however, have consistently earned significant positive returns. Furthermore, the performance of commodities varies in the phases of monetary and business cycles. Although commodity futures distributions are commonly acknowledged to exhibit positive skewness, the authors find minimal evidence of skewness in the commodity return distributions. Finally, the authors find that, on average, the volatility and kurtosis of individual commodity contracts are comparable to those of individual large-cap stocks.

- 2007b. "What Every Investor Should Know about Commodities, Part II: Multivariate Return Analysis." Journal of Investment Management, vol. 5, no. 3 (Third Quarter):40-64.

The authors evaluate the return distribution properties of 27 commodity futures contracts over the period January 1965 through February 2005. They find that, on average, commodity futures have virtually no correlation with stocks and bonds; the correlation varies somewhat, however, by commodity type and in the phases of the business cycle. The benefits of commodities emanate from their diversification properties, which are maintained during turbulent market environments. Finally, commodities are shown to offer a hedge for inflationary pressures; energy, metals, cattle, and sugar offer the best hedge.

Keynes, John Maynard. 1930. A Treatise on Money, Volume 2. New York: Macmillan \& Co.

Keynes conducted the first serious investigation of the term structure of commodity futures prices. Because of time discounting, one might expect farther-dated futures prices to be higher than neardated prices. In many instances, however, the relationship is backward (farther-dated futures are cheaper), which affords speculators a profit opportunity. Sparking a debate that continues to the present, Keynes referred to this phenomenon as normal backwardation- "normal" because, in his view, producers of commodities rely on hedging (by taking short futures positions) more than do consumers (by taking long futures positions). Thus, speculators, taking the other side of the producers' trade, can earn a risk premium or insurance premium through a long position in backwardated futures. The "insurance" is the guarantee of a sales price to the producers, who can thus manage their business risk. 
The New Palgrave Dictionary of Money and Finance explains as follows: "Keynes and Hicks explained the existence of normal backwardation on technological grounds. That is, . . producers must look much further ahead than consumers, because the former may have already committed [capital] to production while the latter have a freer hand about acquiring the commodities. Thus, there exists a greater desire to cover planned production (supplies) than ... planned consumption (demand), [so] hedgers ... have a tendency to be [net] short ...." (p. 107 of the 1992 edition). [Adapted from Laurence B. Siegel, “The Commodity Risk Premium: An Annotated Bibliography,” unpublished (2006).]

Ma, Christopher K., Jeffrey M. Mercer, and Matthew A. Walker. 1992. "Rolling Over Futures Contracts: A Note." Journal of Futures Markets, vol. 12, no. 2 (February):203-217.

This article studies the time-series properties of artificial price series that are created when prices from separate futures contracts are linked. Implicit in the creation of an artificial time series is the choice of rollover method, which involves the point in time at which the current contract is rolled to the next and whether to adjust the price level of the contract being rolled into upon rollover. The evidence indicates that risk and return measurements among several actively traded futures contracts are not robust to the various methods.

Marshall, Ben R., Rochester H. Cahan, and Jared M. Cahan. 2008. "Can Commodity Futures Be Profitably Traded with Quantitative Market Timing Strategies?” Journal of Banking E̋ Finance, vol. 32, no. 9 (September):1810-1819.

"Quantitative market timing strategies are not consistently profitable when applied to 15 major commodity futures series. We conduct the most comprehensive study of quantitative trading rules in this market setting to date. We consider over 7,000 rules, employ two alternative bootstrapping methodologies, account for data snooping bias, and consider different time periods. We cannot rule out the possibility that trading rules complement some other trading strategy or that some traders may have success using a specific rule on its own, but we do conclusively show that none of these rules beat the market any more than expected given random data variation." (p. 1810)

Miffre, Joelle, and Georgios Rallis. 2007. "Momentum Strategies in Commodity Futures Markets." Journal of Banking E Finance, vol. 31, no. 6 (June):1863-1886.

"This article tests for the presence of short-term continuation and long-term reversal in commodity futures prices. Although contrarian strategies do not work, the article identifies 13 profitable momentum strategies that generate 9.38 percent average return a year. A closer analysis of the constituents of the long-short portfolios reveals that the momentum strategies buy backwardated contracts and sell contangoed contracts. The correlation between the momentum returns and the returns of traditional asset classes is also found to be low, making the commodity-based relativestrength portfolios excellent candidates for inclusion in well-diversified portfolios.” (p. 1863)

Mouakhar, Tammam, and Mathieu Roberge. 2010. "The Optimal Approach to Futures Contract Roll in Commodity Portfolios." Journal of Alternative Investments, vol. 12, no. 3 (Winter):51-60.

"This article discusses the necessity of managing the futures contract roll and argues that most commodity index providers set futures rollover rules in an inefficient manner. Generally, most index providers roll futures by replacing the next futures contract to reach maturity with the subsequent futures contract to do so. Depending on the curvature of the commodity futures term structure, such a practice might be acceptable or might lead to automatic losses. This article presents an optimal approach that maximizes gains with a term structure in backwardation and minimizes losses with a term structure in contango. The proposed approach is independent of the position held by the investor (i.e., it dictates the optimal way to roll a short or a long position). The benefits of this approach are 
illustrated by comparing the performance using this approach to that of the standard approach to rollover. The comparison is done both at the individual commodity level and at the portfolio level. Results confirm the crucial importance of handling roll operations in commodity futures investing and show that an optimized approach to roll could improve performance." (p. 4)

Ng, Victor K., and Stephen Craig Pirrong. 1994. "Fundamentals and Volatility: Storage, Spreads, and the Dynamics of Metals Prices.” Journal of Business, vol. 67, no. 2 (April):203-230.

"The theory of storage implies that inventory and demand conditions affect (a) the variances and correlations of commodity spot and forward prices and (b) the spread between spot and forward prices. For four industrial metals and one precious metal over the 1986-1992 period, the observed relationships between the spread and the variances and correlations of spot and forward prices are consistent with the theory. Because the close connection between spreads and real supply-and-demand conditions is well documented, the results strongly suggest that fundamental factors determine the dynamics of metals prices." (p. 203)

Opdyke, Jeff. 2010. "Rethinking Gold: What If It Isn't a Commodity After All?” Wall Street Journal (21 August):B1.

The author cites research from Ibbotson Associates showing that the correlation between gold and the U.S. dollar has been -0.65 over the past 30 years. Since 1978, the correlation between gold and U.S. inflation has been 0.08 . Thus, the author argues, gold is not a commodity-in the consumption sense-but is a currency.

Pindyck, Robert S. 2001. “The Dynamics of Commodity Spot and Futures Markets: A Primer.” Energy Journal, vol. 22, no. 3 (July):1-29.

Pindyck analyzes commodity spot and futures markets from the standpoint of inventory theory. Inventories exist to reduce costs to producers and consumers: They reduce the cost to the producer of adjusting production to meet demand; they similarly reduce costs to the consumer. There are, therefore, two interrelated commodity markets: a market for the commodity itself (the spot market) and a market for the service of storing it (reflected in the futures market). These markets must be in, or tend toward, equilibrium with each other, and backwardation/contango is the mechanism by which equilibrium is reached. A larger degree of backwardation induces the real (nonfinancial) provider of storage services to store more of the commodity. Pindyck shows evidence that when storage is especially valuable - for heating oil, for example, during a cold spell when the oil is in short supplythen backwardation (and the profit from investing in commodity futures) is especially pronounced. The "convenience" referred to in the literature on convenience yield is thus far more than mere convenience; it is a vital economic component of the production/consumption cycle and can have a substantial dollar value. [Adapted from Laurence B. Siegel, "The Commodity Risk Premium: An Annotated Bibliography," unpublished (2006).]

Schneeweis, Thomas, and Richard Spurgin. 2003. "Quantitative Analysis of Hedge Fund, Managed Futures and Mutual Fund Return and Risk Characteristics." In Evaluating and Implementing Hedge Fund Strategies, 3rd ed. Edited by Ronald A. Lake. London: Euromoney Institutional Investor.

The authors evaluate the returns of hedge funds, managed futures, and mutual funds (stocks and bonds) over the 1996-2002 period. They find that each of these asset classes has a unique risk and return structure. They find that the returns to commodity trading advisers have low correlations with the returns of stock and bond funds, whereas the majority of hedge funds are positively correlated. 
Schneeweis, Thomas, Richard Spurgin, Satyabrota Das, and Melissa Donohue. 2008. "Comparing Commodity Indices: Multiple Approaches to Return.” Alternate Investment Analytics, LLC, Research Report.

"This review provides a summary of the features and methodologies of the major commodity indices available to investors. It also examines the return factors possible in a commodity index. Finally, the report describes and analyzes market conditions that will be favorable and adverse for the major commodity indices." (p. 4)

Shen, Qian, Andrew C. Szakmary, and Subhash C. Sharma. 2007. "An Examination of Momentum Strategies in Commodity Futures Markets.” Journal of Futures Markets, vol. 27, no. 3 (March):227-256.

"Commodity futures and equity markets differ in several important respects. Nevertheless, it was found that momentum profits in commodities are highly significant for holding periods as long as nine months, and returns to momentum strategies are roughly equal in magnitude to those that have been reported in stocks. The profits documented are too large to be subsumed by transactions costs. Although the momentum strategies appear to be quite risky, their profitability cannot be fully accounted for in the context of a market factor model. Further, it is shown that momentum profits eventually reverse if positions are maintained long enough after portfolio formation.” (p. 227)

Stoll, Hans R., and Robert E. Whaley. 2010. "Commodity Index Investing and Commodity Futures Prices." Journal of Applied Finance, vol. 20, no. 1 (Spring):7-46.

"Recently, commodity index investing has come under attack. A Staff Report by the U.S. Senate Permanent Subcommittee on Investigation (hereafter, the 'subcommittee report') . . . finds that there is 'significant and persuasive evidence to conclude that these commodity index traders, in the aggregate, were one of the major causes of "unwarranted changes"-here increases-in the price of wheat futures contracts relative to the price of wheat in the cash market.' The purpose of this study is to provide a comprehensive evaluation of whether commodity index investing is a disruptive force not only in the wheat futures market, in particular, but in the commodity futures market in general. We conclude that: a) commodity index investing is not speculation; b) commodity index rolls have little futures price impact, and inflows and outflows from commodity index investment do not cause futures prices to change; and, c) the failure of the wheat futures price to converge to the cash price at the contract's expiration has not undermined the futures contract's effectiveness as a risk management tool.” (p. 7)

Szakmary, Andrew C., Qian Shen, and Subhash C. Sharma. 2010. "Trend-Following Trading Strategies in Commodity Futures: A Re-Examination.” Journal of Banking E Finance, vol. 34, no. 2 (February):409-426.

"This paper examines the performance of trend-following trading strategies in commodity futures markets using a monthly dataset spanning 48 years and 28 markets. We find that all parameterizations of the dual moving average crossover and channel strategies that we implement yield positive mean excess returns net of transaction costs in at least 22 of the 28 markets. When we pool our results across markets, we show that all of the trading rules earn hugely significant positive returns that prevail over most subperiods of the data as well. These results are robust with respect to the set of commodities the trading rules are implemented with, distributional assumptions, data mining adjustments and transaction costs, and help resolve divergent evidence in the extant literature regarding the performance of momentum and pure trend-following strategies that is otherwise difficult to explain.” (p. 409)

Tang, Ke, and Wei Xiong. 2010. "Index Investment and Financialization of Commodities." Working paper, Princeton University and NBER.

"This paper finds that concurrent with the rapid growing index investment in commodities markets since early 2000s, futures prices of different commodities in the U.S. became increasingly correlated with each other and this trend was significantly more pronounced for commodities in the two popular 
GSCI and DJ-UBS commodity indices. This finding reflects a financialization process of commodities markets and helps explain the synchronized price boom and bust of a broad set of seemingly unrelated commodities in the United States in 2006-2008. In contrast, such commodity price co-movements were absent in China, which refutes growing commodity demands from emerging economies as the driver." (p. 1)

Wang, Changyun, and Min Yu. 2004. “Trading Activity and Price Reversals in Futures Markets.” Journal of Banking E Finance, vol. 28, no. 6 (June):1337-1361.

"We use the standard contrarian portfolio approach to examine short-horizon return predictability in 24 U.S. futures markets. We find strong evidence of weekly return reversals, similar to the findings from equity market studies. When interacting between past returns and lagged changes in trading activity (volume and/or open interest), we find that the profits to contrarian portfolio strategies are, on average, positively associated with lagged changes in trading volume, but negatively related to lagged changes in open interest. Our results suggest that futures market overreaction exists, and both past prices and trading activity contain useful information about future market movements. These findings have implications for futures market efficiency and are useful for futures market participants, particularly commodity pool operators.” (p. 1337) 